\title{
Migrant Economic Behaviors: Causal Effects of Health Education on Saving Rates, Social Medical Insurance, and House Purchasing
}

\section{Dong Chunfeng}

Shanghai University of Finance and Economics

JIALU YOU ( $\square$ LunaYou@163.sufe.edu.cn)

Shanghai University of Finance and Economics https://orcid.org/0000-0002-3132-4003

Jinhua Zhang

Shanghai University of Finance and Economics

\section{Research}

Keywords: Health Education, Social Medical Insurance, House Purchasing, Saving Rates, Healthy China Policy

Posted Date: July 22nd, 2021

DOI: https://doi.org/10.21203/rs.3.rs-658517/v1

License: (c) (i) This work is licensed under a Creative Commons Attribution 4.0 International License. Read Full License 


\section{Migrant Economic Behaviors: Causal Effects of Health}

\section{Education on Saving Rates, Social Medical Insurance, and}

\section{House Purchasing}

Chunfeng Dong ${ }^{1}$ JialuYou $^{11}$ Jinhua Zhang ${ }^{1}$

1. Institute of Finance and Economics, Shanghai University of Finance and Economics, Shanghai 200433, China 


\title{
Migrant Economic Behaviors: Causal Effects of Health \\ Education on Saving Rates, Social Medical Insurance, and \\ House Purchasing
}

\begin{abstract}
Backgrounds: Health China as the essentials policy with advancing Global Health, making contributions to decline the inequality between rural and urban health education, and recovering the domestic markets after Coronavirus. The goal of this study is to evaluate the economic returns on health educations in a developing country.
\end{abstract}

Methods: We combine life cycle mechanisms and safety beliefs to evaluate continuous values of health education from 720,900 migrants' economic behaviors through the Extend Regression Model, average treatment effects, and heterogeneous treatment effects robust empirically approach.

Results: We find that health education positively affects participation in social medical insurance and house purchasing. In contrast, the relationship between health education and saving rates is an inverted ' $U$ ' shape. Heterogeneous treatment effect empirically robust account for heterogeneity in the previous generation and young generation; urban citizenship and rural citizenship continuous effects of health education.

Conclusion: The finding suggests that health education stimulates immigrant consumption behaviors; however, extra health education is not a wise policy. Rural-urban citizenship acquisition bias is a significant factor of health education effects differential.

Keywords:

Health Education, Social Medical Insurance, House Purchasing, Saving Rates, Healthy China Policy

JEL CLASSIFICATION

I15; D14; R23

\section{Introduction}

Immigration has always been a topic of concern and controversy in world economics. We explore the migrant economic future behaviors in China. China migrants contribute to the urbanization from 1984. However, like a developed country and another developing country, the disputes about migrant economic behaviors should be more attention.

In 2020, China's GDP first broke 100 trillion yuan; cheap labor resources from immigrants mainly contributed the massive economic growth and urbanization. According to the 2015 Chinese census data, immigration reached 241 million and accounting for $18 \%$ of the total population. The flowing of labor resources brings the geographical imbalance of economic development. Under the standard world policy of foreign demands transformation from domestic demands, the research of immigration economic behavior is still an important determinant of economic recovery and stimulating consumption. China's immigration has a unique experience history from 1984 to now, making it valuable to research.

Figure 1 presented the province migrants in China in 2015(data source from Chinese census data). There were 2.47 million immigrants in China. The thick lines represent the number of immigrants between provinces, representing the labor resource flowing to the large eastern scale 
and Beijing (BJ). With immigration increased from 128 million in 1978 to 830 million in 2019, China has experienced rapid urbanization and economic prosperity. It means migrants' economic status is essential for China's development. However, high saving rates and insufficient consumption are still significant obstacles for economic growth in developing countries, especially issued China's policy circus economy. According to the data, if increasing the consumption rates of immigration by $10 \%$, the GDP will increase to five thousand ${ }^{2}$.That means analyzing the economic behaviors of immigration and stimulating the wiliness of immigration consumption will be a new source of economic growth for China's Circular Economic policy.

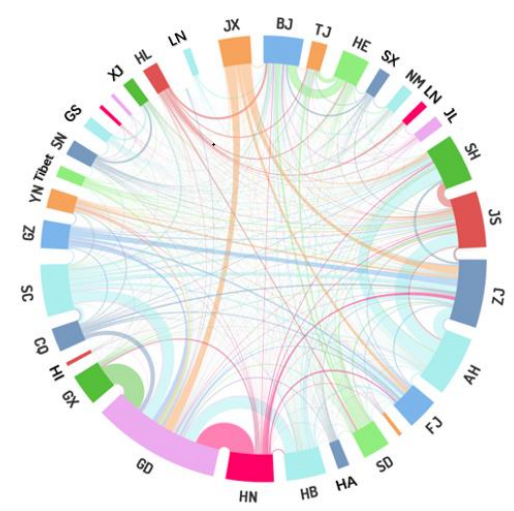

FIGURE one Provinces migrants ${ }^{3}$

What factors affect immigrant's economic behavior? How to stimulate the consumption of immigrating? Most of the literature discussion on immigration economic behavior focused on the social capital and education (Xindong Xue and W. Robert Reed 2020). While some literature has provided potential evidence with the link between health and economic development (Weathers and Stegman 2012; Edward Miguel 2016; Jeremiah Hurley, 2020), the correlation between health and immigration economic behavior remains an unexplored topic in the economic fields. According to the existing several channels of health effects upon the economy at present. Deaton (2013) demonstrated that economic development is that higher-income levels correlate strongly with longer life expectancy, lower infant mortality, and more heightened health awareness. Font and Cowell (2019) focused on the health gap caused by inequality income with immigration. They showed that well health is a pre-requisite for obtaining wealth. About the relationship between health and individual economic behaviors, One potential view is that lack of health insurance has prompted higher precautionary savings, especially with immigration (Chamon \& Prasad, 2010), similar empirical research, which also involved developing country. Wagstaff and Pradhan (2005) study a case in Vietnam invoked that health positively affects household consumption. Shuang and Gan (2011) investigated the impact of health on individual food consumption among rural households. About the total consumption rates. Weimin Zhao (2018) found that social insurance significantly promotes rural residents' daily consumption, which means health through the social security net to decrease immigration saving rates. In addition, the current research is only based on the macroeconomic views-health policy to evaluate the links between health and consumption behaviors; none of the literature from microeconomic views provides more substantial evidence that individual health education affects immigrants' economic actions in the developing country. This

2 Data Source: China Migrants Dynamic Survey (CMDS).

${ }^{3}$ Data Source: China one-percent national sample census at 2015 
study provides an empirical test about the health-savings hypothesis that health education has increased immigration future-orient economics behavior using individual immigration data (CMDS). Besides, we explored health education's influence on economic behaviors through three aspects: the proposition of the health education-saving hypothesis, health education-insurance hypothesis, and health education-purchasing house hypothesis.

Firstly, we review the background and literature on health education policy, which used a variety of instruments for measuring health education. From that literature, we adopt the number of participating in the health education at current's community as tools to measure the immigrating health education, which through assignment to measure immigrating health education, the higher score $^{4}$ means more vital health education(Weiss, 2015). This criterion separates that immigration health education both overall and distinguishing automatically. Then test how this health education differ correlate with future-oriented immigration behaviors such as saving rates, social health insurance, and purchasing a house through OLS and Probit Regression. Finally, we also attempt to explore whether differences in health education cause these differences behaviors. For example, the lowest health education immigration, whether more tend to save, not participating in social health insurance, and purchasing house behavior.

On the contrary, more robust health insurance would consume more consumption, participate in social health insurance, and purchase houses. However, the regression of OLS and Probit have found a strong correlation between health education and future economic behavior, which do not attenuate with the inclusion of numerous individual character's variable, country, and job controls. However, this effect is heterogeneous across two catalogs of immigration: urban to urban; rural to urban. Finally, compared to the two catalogs immigration, health education mainly promotes urban to urban immigration consumption. The rural to urban immigration had not benefited significantly from urban to urban immigration.

Compared to other researches that focus on the effects of migrant's economic behaviors, including health insurance and grocery purchasing, on health. This paper's contributions fill the literature gap of health education's impact on economic behaviors. This paper gave significant empirical evidence returns to health education on immigration economic behaviors. Through the microeconomic CMDS data, health education positively influenced immigrants' behavior, including stimulating consumption, social health insurance involvement, and purchasing a house. Secondly, we predict that migration from urban to urban has a more significant effect than rural to rural by adopting large immigrant samples with 720,900. Third, we suggest that health education affects a channel independent of human capital attitudes towards savings, social health insurance, and purchasing house behavior. The WHO and UN commission should awareness the importance of health education for economic recovery and prosperity.

The article proceeds as follows: Section 2 reviews the policy and related literature about health education's impact on future economic behavior. Section 3 detailed showed the empirical methods and the data. Section 4 presented the casual effects of health education. Section 5 implications the findings for contributions in economics fields and interpret the results.

\section{Background}

\subsection{The Policy of Healthy China}

\footnotetext{
${ }^{4}$ Nine scores are perfect. Zero is the lowest score.
} 
The global industry chain is reconstructing caused by Coronavirus, which negatively affected international investment and exports. Hence, stimulating consumption is the new driving force to improve the current economic slowdown. Especially, improving the potential consumption with immigrating is new growth points for future economic development. Fig.2 reports the proportion of saving rates on the Gross Domestic Product (GDP) ranges from 1988 to 2018. China accounts for the highest saving rates from 1998. Korea is second in terms of saving rates, and the USA has low saving rates. From 2008 to 2018, China and India's saving rates drop to $44.39 \%$ and $31.1 \%$, respectively. On the contrary, Korea, Japan, and the USA account for the saving rates increased by $35.85 \%, 27.84 \%$, and $18.62 \%$, which means a decrease in saving rates, incentivized labor productivity and economic development.

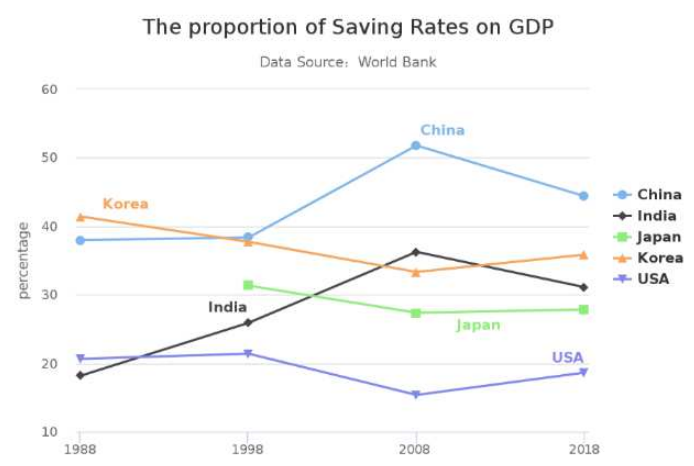

FIGURE2 The proportion of saving rates on GDP

Fig.3 illustrates the consumption elasticity of the immigrating and urban residents in China. Consumption level between urban residents and immigration upward trend from 2013 to 2019. However, there exist significant consumption gaps between immigration and urban resident. On the other hand, immigrating also has potential consumption in the future. How to release the consumption potential of immigrating? Improve social medical insurance through health education to stimulate consumption with immigrating, which is the key to expanding the domestic demand in the future.

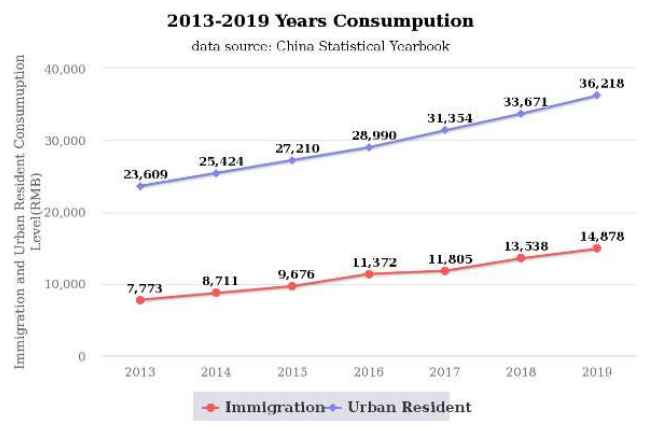

FIGURE 3 Consumption level between immigration and urban resident ${ }^{5}$

In 2016, China began to make institutional plans for building a health education. China further improved residual health education through the Healthy China initiative policy in 2017, which addresses preventing disease and health. Individual health education inequalities caused by urbanrural integration and the economic burden of illness increased particular propensity to save. Healthy China initiative promotes public health to improve health, reducing the high cost of disease expenses for immigrating. The Immigrants participated in the current community service with health educations, and they do not need to pay any premium. By 2019, China advocated that the resident

\footnotetext{
5 The blue line represented urban resident consumption ; the red line represented immigrating consumption elasticity
} 
health education rates will reach $45 \%$, and health behaviors will reach $30 \%$ by 2030 .

What is more, the government has begun to establish a mechanism for publishing and disseminating health knowledge. Although China gradually changed the residences health education through spreading the retirement insurance system and healthy knowledge lectures, there is still significant segregation between rural and urban health education for a long time. The segregation forced immigration to decrease consumption and increase saving on facing the possible illness.

\subsection{Health education and Economic Behaviors: A Review of Literature}

The literature discussion on the relationship between health education and economic behaviors relatively small but increasing. It mainly focuses on the effectiveness of health education on individual health outcomes, including condoms, medical care, obesity, and daily fruits and vegetables. For example, Resul Cesur (2018) used nationally representative health data in Turkey and showed that health education has positive effects on BMI and obesity in men. They could not find the effects of health education on daily consumption of fruits. Similarly, Duflo (2015) estimated HIV education Program on early fertility and SIT in Kenya confirmed the effectiveness of reducing the SIT. Under distribution effectiveness, some literature focuses on the correlation between health education and welfares; Giulia (2020) claimed that Italy's Global Health Education reduces health inequality and social justice. Dupas (2016) shows that improved health education in low-income countries will improve well-being and promote economic development. However, some studies reported that education has no or fewer effects on health behaviors and welfares. Katharina Janke(2018) used QLFS data to exploring the relationship between education and chronic health in UK. They found that extra education has no impact on the prevalence of chronic illness. Zajacova A (2018) suggested that health education reproduces the inequality from the generations.

Above those kinds of literature, there no consensus about the effects of health education effects and economic behaviors, especially about the immigrants' health education studies still opaque. Hence, we based on the life cycle hypothesis to explore the mechanism of the health education effects (Jan Boone, 2019). The life cycle hypothesis stems naturally from two mechanisms concerning a health education-induced bias in time perception. Suppose an immigrating is deciding whether to save now, in exchange for security ${ }^{6}$ in the future. If the immigrating do not worry about the safety network, they will prefer to consume or save. Supposed the immigrating conditional expectation at times $t$ defined as $E_{t}$; the consumption represented $C_{t} ; Y_{t}$ defined as immigrating income; $W_{t}$ denotes the uncertain growth part from income. $R_{t}$ Is presented interested rates. If immigrating exchange for the security rates $\delta$, then immigrating prefer to consumption or saving only if:

$$
\begin{aligned}
& \max _{t} \sum_{t=0}\left(\frac{1}{1+\delta}\right) U\left(C_{t}\right) \\
& \text { s.t. } W_{t+1}=W_{t}\left(1+R_{t}\right)-C_{t}+Y_{t}
\end{aligned}
$$

The first way that healthy education possibly affects economic behavior is by changing how distant future safety events feel. For example, it seems plausible that healthy education brings about confidence with future illness and retirement events as if they were happening at currents, would lead immigrating to less worry about future safety net events. Indeed, several literary appear to prove it. Muller (2017) suggested that life expectancy in the US has a more robust coefficient with income and saving; residents prefer saving in the present and aim to make their feel safer and

\footnotetext{
${ }^{6}$ Retirement safety; healthy safety
} 
confident when the emergency happened. Hilary Hoynes (2006) has consciously proved health care utilization and health status impacts immigrating income and saving, since welfare reform through effects on family healthy awareness to decide to save. Indeed, we cannot directly predict health literacy's effects on saving or consumption because health literacy as relief from the life cycle could potentially affect economic behaviors (Jacob Goldin, 2020). If we worry about healthy security events in the future, immigrating who obliges themselves to save may make illness more distant.

In the context of the precaution saving model, this could be represented either through the security rates. That is, supposed that weak and strong health education lead immigrating hold utility security rates $\mathrm{U}(\delta)^{\prime}<U(\delta)^{\prime \prime}$, which would bring in different willingness to save:

$$
E_{t}\left(c_{t+1}-c_{t}\right)=\left[-\frac{\mathrm{U}(\delta)^{\prime}}{U(\delta)^{\prime \prime}}\left(\frac{R_{t}-D}{1+R_{t}}\right)-\frac{\frac{\mathrm{U}(\dot{\delta})^{\prime}}{U(\delta)^{\prime \prime}}}{2}\right] E_{t}\left[\left(c_{t+1}-c_{t}\right)\right]>0
$$

It is easy to see how health literacy affects the decision with saving and consumption. Therefore, we propose the first proposition:

Proposition 1: Health education has a negative impact on a decision with saving rates.

The second way health education possibly affects future choices is by leading immigrants to have more or less confidence in future life. Migration with more health education would lead to more confident beliefs about pension or living security. For example, confidence beliefs increased attention to living conditions. Recently, the literature has found that health effects on the living expectation under uncertainty. Indeed, many individuals expect to live longer than actuarial life expectancy (Péntek et al., 2014; Rappange, 2016). Migration who are healthier education may improve the living condition, making them livelonger. For example, Neuman (2008) found that health awareness positively affects self-reported well-being but affects health outcomes. Stefan Felder (2020) shows that an increase in health education has influenced the insurance effect and increases precautious awareness, while it renders the living condition investment more critical.

If this confidence belief effect is actual under uncertainty, which leads to improving living conditions, then strong health literacy migrating will be less willing to save. To see this, assume strong, healthy education migrating (who must distinct the future and present under uncertainly) hold more confidence beliefs in the future than migrating of weak health literacy.

Moreover, if $\mathrm{E}\left(\delta_{t}^{\prime}\right)$ and $\mathrm{E}\left(\delta_{t}^{\prime \prime}\right)$ are the confidence beliefs of weak and strong health literacy migrating, then established that an invest decision-maker with confidence beliefs $\mathrm{E}\left(\delta_{t}^{\prime \prime}\right)$ would attract less attention to future security than one who holds beliefs $\mathrm{E}\left(\delta_{t}^{\prime}\right)$.

$$
E_{t}\left[c\left(\delta_{\mathrm{t}}^{\prime \prime}\right)-c\left(\delta_{\mathrm{t}}^{\prime}\right)\right]>0
$$

In other words, since the discount with health literacy implies that the value of future rewards is a strictly convex function of time, uncertainty about the pension security payoffs makes saving more attractive. Noted that equation 3 is not only saving critical. It would have the same effect on savings as mechanisms one and two: migration that lower health education would save, plan more, and consume less (purchasing house, health security). Therefore, the proposition two and three as follows:

Proposition 2: Health education positive effect on participating in social medical insurance.

Proposition 3: Health education positive effect on purchasing the house.

The paper will present empirical findings that test three hypotheses and then a more general discussion of health literacy and economic behavior. 


\section{Empirical Strategy}

\subsection{Data}

To investigate the coefficient between immigrating health education and future economic behavior at the micro-level, we adopt data from the China Migrants Dynamic Surveys (CMDS). The CMDS major represented the immigrating healthy dataset in China, an annual longitudinal survey of Chinese immigrating communities, families, and individuals launched in 2009 by the Institute of National Health Commission. A multistage, random cluster, the proportion to scale sampling method at each province, conducts the survey related to migrating information (e.g., migrant scope, immigrating employment, social security, income and expenditure, basic health public service with community, social integration and health service). This dataset covers 31 provinces and Xinjian production and construction corps of China immigrating in annual. There are approximately two hundred thousand households in the annual survey, which collects a representative sample of about 209.37millons in 2014. It contains the immigrating for five hundred thousand; the total sample in 2016 about 169000 observations, which covers 450,000 immigrating family observations; and the sample of the 2017 surveys is 170,000 family observations, including four hundred and fifty thousand individuals. The rural level sample covers 10000 observations; 10000 observations, 8500 observations, and 85000 observations in 2014; 2015; 2016; 2017.

We adopted the CMDS dataset has three advantages. The main reason why we choose CMDS is that its period meets our research needs. From 2014 to 2017, some provinces in China gradually have aware of health education. It provides us distinct behavior from future and precocious behavior. Second, our research focus on immigration. The CMDS only collects individual, family, and community-level longitudinal data with immigrating, supporting our purpose well. Lastly, the CMDS survey includes all health conditions and economic conditions with immigrating. It makes investigated possible that examine the relationship between health literacy and future economic behavior.

In addition, we merged the cross-sectional data into a diverse cross-section from 2014 to 2017. Then drop out the unvalued answered, the final sample for our analysis contains 720,900 observations for all four years, accounting for $96.64 \%$ of the four-year total sample.

\subsection{Methods}

\subsubsection{A Sequential Decision Models}

The essential of sequential decision models are each decision node. At each node, agents will consider the benefits and investment costs to make the next decision. The sequential decision models as follow:

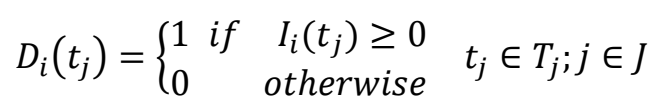

Equal (5) presents general sequential decision models, where $I_{i}\left(t_{j}\right)$ is the perceived cost for agents at a node $\mathrm{j}$; $J$ represents the sets about possibly of agents node transition. We assume $T_{j}=$ 0 means agents never make decision nodes $j ; T_{j}=1$ means agents make least the node transition from $j$ or $j+1$. Figure 4 description the nodes transition. Where $j=t w o, T_{2}=\{0,1\}$ represents agents accept health education in $\mathrm{j}=$ one, $\mathrm{T}_{2}=\{(0,0),(1,0),(1,1)\}$ represents agent's health education node transition in $\mathrm{j}=1$ and $\mathrm{j}=2$ respectively, according to Heckman (2016), all decision nodes as:

$$
Y_{l}^{\dot{h} k}=\rho_{i}^{h k}(X)+C_{i}^{h k}
$$


Where $X$ and $C_{i}^{h k}$ means observed and continuous choice outcome in the sequential choice model. To estimate the health education returns at each choice node from Figue1, we use average treatment effects ${ }^{7}$ to analyze agents' two transition nodes (Callaway and Sant'Anna, 2019). Likewise, through heterogeneous treatment effects, to estimate the intergeneration transmission and resident types continuous values at two transition nodes (Ben Jann, 2015).

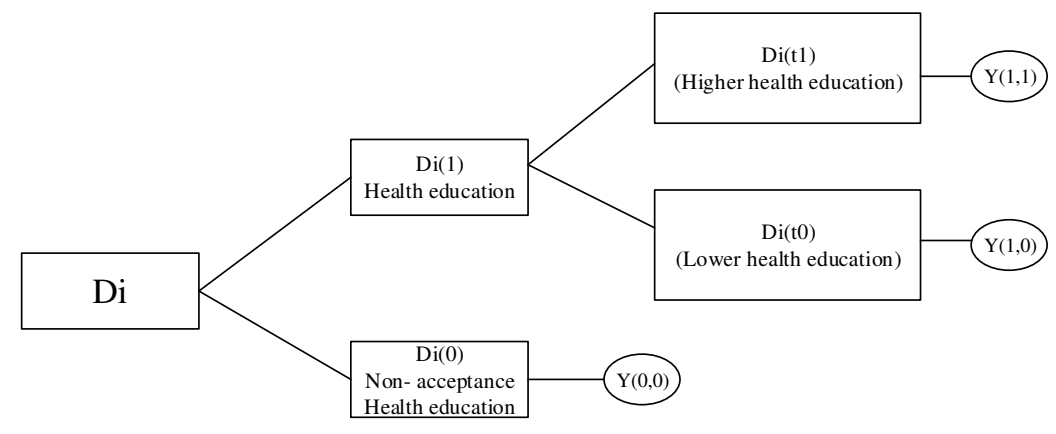

Figure 4 Health education choice

\subsubsection{The Effects of Health Education on Economic Behaviors Analysis}

In this section, we introduce the OLS and Probit regressions on the family-level in CMDS datasets, which ran from 2014 to 2017. The immigrating family was asked about the income and expenditure monthly. This allows us to calculate the saving rates across the diverse cross-section. This sample has a unique advantage in that it represented the immigrating future economic behavior that makes a cross-provincial comparison. It is also based on mechanism one with the life cycle hypothesis. We adopted the following model to explore our propositions:

$$
Y_{i}=\beta_{0}+\beta_{1} H E_{i}+\beta_{2} X_{i}+\mu_{i}
$$

Where $Y_{i}$ define as family saving rates at monthly, purchasing social health medical insurance and purchasing house; $H E_{i}$ represent the individual's health education level; $X_{i}$ is individual control variables and $\mu_{i}$ define as a random disturbance. We estimate the effect probit models of propensity to save or consume, regressed on the future economy of that individual health education, and control individual characteristic variables; country and year. Effectively, this analysis test proposition 1: whether health education positive effects on the save rates? This allows me to examine the effect of health education on saving's behavior by how much an immigrant participates in health education. To a limited extent, this also helps us investigate proposition 1: whether health education acts as a marker that stimulates consumption or whether health education itself directly affects saving behavior. Besides, it is considered that participation in social medical insurance and purchase of housing are binary variables, we will use probit model to analyze the impact of health education on social health medical insurance and purchasing house behavior. Together, these results allow me to investigate proposition 2: whether the saving is behavior results extend to participation in social health security behaviors and purchasing house behavior in developing countries.

\subsection{Variable Declaration}

\subsubsection{Depend variables}

While in this paper, all regression focuses on future economic behavior. According to the effects of weak and more vital health education on the life cycle hypothesis, it may be essential to choose the dependent variables. A weak health education might be the presented of unsafety belief, and they prefer to save, plan more, and consume less. A more critical criterion might be the presence of safety

${ }^{7} \operatorname{ATE}\left(t_{j}\right)=\int Y_{i}\left(t_{j} ; 1\right)-Y_{i}\left(t_{j} ; 0\right) d f(X, \theta, \epsilon)$ 
belief, which would include purchasing health security and housing, enjoy the moment. For this reason, we adopted three aspects to examine future economic behaviors, which correlated with saving rates, social medical insurance, and house purchasing. The dependent variables as follows:

Saving Rates (SR). We used the index of immigrating monthly expenditure and income to calculate the saving rates from the CMDS survey.

Social Medical Insurance (SMI). The measurement of purchasing social medicine insurance from the CMDS survey. The question is, "what kind of social health security do you currently participate in?" which contains new rural cooperative health security, urban and rural residents' cooperative health security, urban residents' health security, and urban employee health security. We construct a dual dummy variable of whether to purchase social health security; purchasing health security represents a value of one, other 0 .

House Purchasing (HP). Aim to the variable of purchasing the house, and we measure CMDS surveys' values and the house living type, such as low-rent or welfare houses; the rent house; purchasing a house. Briefly calculate, we also construct the dual dummy variable of purchasing the house in the immigrating family's economic expenditure. Value 1 is defined as purchasing a house, otherwise is zero.

The reason for selecting three independent variables with saving, social medical security, and house purchasing is there are both central to the two mechanisms of economic behavior and representing the attitude of future consumption.

\subsubsection{Independent variable}

Health Education (HE). In all the regressions based on the independent variable of central safe security is the health education level. According to the international healthy education commission, we adopted the measurement of health education (Simonds, 1974). The U.S. Department of Health and Human Services (DDS) described healthy education as the individual health decision ability after obtaining and understanding the health information they needed. The World Health Origination defined health education as a precautious illness and making a correct judgment to improve their health. In this paper, we adopt the CMDS survey measurement (whether participated in community health education in the past year? For example, occupation disease prevention; HIV; reproductive health and contraception, tuberculosis prevention, smoking control, mental health, chronic disease prevention, maternal and child health care/eugenics). According to the Seven-Liker points and (Toçi, 2014; Berens EM, 2016) methods to measure the migrants' health education. We suggested that more potent healthy education would participate in numerous health education at community; a criterion distinct weak and robust was a variable assignment for the participant number. As long as the immigrants participate in health education, we assign 1 point for variables. The score with nonacceptance health education is zero, and accept health education range from 1 to 9 . We divided at median scores into lower health education and higher health education in accepting the health education samples. Therefore, differences between whether acquisition health education and health education level were the most direct test of the three propositions.

\subsubsection{Control variables}

Considering the potential variables would affect the relationship between health education and economic behaviors. We control some variables in the regression. The control variables cover last month's salary income; gender, age; years of education; whether to have a spouse; years of immigrating, family size, occupation type, employment (Beck et al., 2010). We also consider the migrant scope mainly includes four types, inter-provincial mobility, intra-provincial inter-city 
mobility, and intra-city inter-county mobility. It is noted that the proportion of inter-provincial mobility accounts for over $60 \%^{8}$, and most of them are in eastern China, so we also control the migrant years and scope.

Table 1 showed the descriptive statistics of our sample. After adopting the selection criteria, the finally total sample is 720900 observations. Columns 1, 4, and 5 reported the number of observations of the base sample of independent variables, dependent variables, and control variables. Columns 2 represented the means of the variables used in our regression, and columns 3 reported the standard deviations in parentheses.

Table 1 Descriptive statistics

\begin{tabular}{|c|c|c|c|c|c|c|}
\hline Variables & Definitions & Obs. & Mean & Std. dev. & Min & Max \\
\hline SR & $\begin{array}{l}\text { household monthly income saving } \\
\text { rate }\end{array}$ & 720900 & 35.52 & 26.14 & 0.00 & 99.60 \\
\hline SMI & $\begin{array}{l}\text { Purchased social medical insurance } \\
\text { for } 1 \text {, Otherwise } 0 .\end{array}$ & 720900 & 0.89 & 0.31 & 0.00 & 1.00 \\
\hline HP & $\begin{array}{l}\text { Buy or build his (her) own house } \\
\quad=1 \text {; Otherwise } 0 .\end{array}$ & 517020 & 0.24 & 0.43 & 0.00 & 1.00 \\
\hline $\mathrm{HE}$ & health education score & 720900 & 3.60 & 2.89 & 0.00 & 9.00 \\
\hline Gender & male $=1 ;$ female $=0$ & 720900 & 0.54 & 0.50 & 0.00 & 1.00 \\
\hline Age & years of age & 720900 & 35.42 & 10.44 & 15.00 & 99.00 \\
\hline Ages & age squared & 720900 & 1363.67 & 828.20 & 225.00 & 9801.00 \\
\hline Married & $\begin{array}{l}\text { The respondent has a husband or } \\
\text { wife and assigns a value of } 1 \text {, } \\
\text { otherwise } 0 .\end{array}$ & 720900 & 0.79 & 0.41 & 0.00 & 1.00 \\
\hline Out year & years of working away from home & 720900 & 5.36 & 5.33 & 0.00 & 81.00 \\
\hline Ttlfam & $\begin{array}{l}\text { the household size of the } \\
\text { respondents }\end{array}$ & 720900 & 3.07 & 1.17 & 1.00 & 10.00 \\
\hline Out fam & $\begin{array}{l}\text { the size of the household population } \\
\text { that follows the respondent away } \\
\text { from home to work }\end{array}$ & 720900 & 2.57 & 1.19 & 1.00 & 10.00 \\
\hline Job type & $\begin{array}{l}\text { the type of occupation the } \\
\text { interviewees work in. }\end{array}$ & 560998 & 3.17 & 1.44 & 1.00 & 6.00 \\
\hline Firm type & $\begin{array}{l}\text { the nature of the workplace of the } \\
\text { interviewees }\end{array}$ & 604772 & 2.48 & 0.63 & 1.00 & 3.00 \\
\hline Work type & $\begin{array}{l}\text { The type of job identity of the } \\
\text { interviewees. }\end{array}$ & 604772 & 1.80 & 0.94 & 1.00 & 3.00 \\
\hline
\end{tabular}

8 Data Source: China Migrant Dynamic Surveys, website: https://chinaldrk.org.cn/wjw/\#/data/classify/subjectService/subject3. 


\section{Results}

This section we first present the empirical results of Health Education Returns through OLS and Probit regression. Moreover, empirically eliminating endogenous of health education and economic behaviors through Extend Regression (ERM) models, finally evaluating continuous variables of health education among average treatments effects and heterogeneous treatment effects in sequential choice fame.

\subsection{OLS and Probit analysis of Health Education Returns}

Saving Rates: The first set of regressions examines the saving behavior. We estimate the coefficient between health education and saving rates by OLS regression. Empirical estimates of equation six are presented in Tables 2. Regression (1) not adds the control variable in first choice node. The coefficient of regression (1) -0.199 can be interpreted as those who accept health education migrants prefer to consume $19.9 \%$, which means health education negatively affects saving rates. Regression (2) further controlled for the personal and social characteristics variables. The coefficient of -0.134 means those who do not accept health education wiliness to save 13.4\% Regression (3) analyze the health education returns for those who accept higher health education; spuriously, health education has no significance effects on saving rates. These results demonstrated that there is an invert $U$ shape between health education continuous variable and saving rates. One possible explanation is that health education for the migrating, which in turn improves their health level, and improves the confidence belief in the future.

Social Medical Insurance: If migrants who have higher health education save less in any given year, then we would expect them to accumulate fewer savings over time. The next set of regressions examines the awareness of participants in social medicine insurance. Table 2 also presented the regressions of purchasing the social medicine insurance economic behavior. Regression (4) does not add the control variables; the evaluation result shows those who accept health education migrant has more than $23.19 \%$ to participate in social medicine insurance. Which implies health education has significantly positive effects on participating in the social medicine insurance. Comparison regression (5) and (6) show that health education still has substantial continuous effects on social health insurance. The coefficient is 0.0955 and 0.0574 , which interprets strong health education as having more awareness to participate in social medical insurance. The possible reason is that improving health education with migrating helps they participate in social health security, which allows them to reduce their future health burden and improve the safety belief for the future.

House Purchasing: The CMDS also asks about the house conditional and whether purchasing a home. If health education affects immigrants' safety belief in the future, this would also affect buying a house behavior and long-run investment. More specifically, if obligatory strong health education immigrates to reduce the future's safety belief, we would conclude that it would lead to more planning, less consumption, and worse condition. To test proposition 3, Table 2 summarizes regression's effects of health education and house purchasing. Regression (7) also not adds the control variables, the results imply those who accept health education has positively impact on house purchasing economic behavior. Compared with regression (8) and regression (9), higher health education immigrating led to $3.61 \%$ and $1.06 \%$ more possibilities of purchasing a house. We see that no matter the first choice node and second node, higher health education always positively affects buying a house behavior. In other words, If immigrating who have robust health education would reduce a safety concern for the future; we could conclude that they expect to purchase a house

Figure 5, Figure6, and Figure 7 represent the AME (average marginal effects) evaluation in all 
health education sequential choice frames. From Figure 5, the AME is -0.1343 and 0.049 in first choice nodes and second choice nodes, respectively. That means the health education marginal effects indifference for whether acquisition health education and health education level. Compared with figure 5 and figure 6 , the continuous marginal health effects diminish for social medical insurance. It means that health education positive impacts of participating social medical insurance is more likely for lower health education groups. However, the continuous values of marginal health effects are increasing for purchasing the house. It predicts that higher health education has a strong willingness to purchase a house.

Table 2 Health education and saving rates, social medical insurance and house purchasing

\begin{tabular}{|c|c|c|c|c|c|c|c|c|c|}
\hline & \multicolumn{3}{|c|}{ SR } & \multicolumn{3}{|c|}{ SMI } & \multicolumn{3}{|c|}{$\mathbf{H P}$} \\
\hline & (1) & (2) & (3) & (4) & (5) & (6) & (7) & (8) & (9) \\
\hline \multirow{2}{*}{$\mathrm{HE}$} & $-0.199 * * *$ & $-0.134 * * *$ & 0.0307 & $0.2319 * * *$ & $0.2221 * * *$ & $0.09522 * * *$ & $0.0574 * * *$ & $0.0361 * * *$ & $0.0106^{* * *}$ \\
\hline & $(0.0578)$ & $(0.0651)$ & $(0.05409)$ & $(0.00523)$ & $(0.0061)$ & $(0.00607)$ & $(0.00534)$ & $(0.0066)$ & $(0.0009)$ \\
\hline \multirow{2}{*}{ Gender } & & $-0.729 * * *$ & $-0.7004 * * *$ & & 0.00218 & 0.00321 & & $-0.0784 * * *$ & $-0.083 * * *$ \\
\hline & & $(0.048)$ & $(0.05334)$ & & $(0.0051)$ & $(0.00623)$ & & $(0.0056)$ & $(0.0067)$ \\
\hline \multirow{2}{*}{ Age } & & $-0.451 * * *$ & $-0.4788 * * *$ & & $0.05447 * * *$ & $0.06289 * * *$ & & $0.0241 * * *$ & $0.0261 * * *$ \\
\hline & & $(0.0184)$ & $(0.0533)$ & & $(0.00182)$ & $(0.00221)$ & & $(0.0022)$ & $(0.0027)$ \\
\hline \multirow{2}{*}{ Agesq } & & $0.0063 * * *$ & $0.00662 * * *$ & & $-0.0007 * * *$ & $-0.0009 * * *$ & & $-0.0002 * * *$ & $-0.0002 * * *$ \\
\hline & & $(0.00023)$ & $(0.000274)$ & & $(0.0000)$ & $(0.00002)$ & & $(0.0000)$ & $(0.0000)$ \\
\hline \multirow{2}{*}{ Married } & & $0.7399 * * *$ & $0.8078^{* * *}$ & & $0.1654 * * *$ & $0.15582 * * *$ & & $0.3633^{* * *}$ & $0.3656^{* * *}$ \\
\hline & & $(0.0835)$ & $(0.0964)$ & & $(0.0083)$ & $(0.0102)$ & & $(0.0103)$ & $(0.0127)$ \\
\hline \multirow{2}{*}{ Out year } & & $-0.1506^{* * *}$ & $-0.1399 * * *$ & & $-0.0040 * * *$ & $-0.0041 * * *$ & & $0.0481 * * *$ & $0.0486^{* * *}$ \\
\hline & & $(0.004)$ & $(0.00568)$ & & $(0.0005)$ & $(0.00061)$ & & $(0.0005)$ & $(0.00062)$ \\
\hline \multirow{2}{*}{ Ttlfam } & & $1.103 * * *$ & $1.0631 * * *$ & & $0.212 * * *$ & $0.0345^{* * *}$ & & $0.024 * * *$ & $0.0192 * * *$ \\
\hline & & $(0.0338)$ & $(0.0391)$ & & $(0.0037)$ & $(0.00452)$ & & $(0.0039)$ & $(0.00477)$ \\
\hline \multirow{2}{*}{ Outfam } & & $-2.202 * * *$ & $-2.161 * * *$ & & $-0.0220 * * *$ & $-0.0248 * * *$ & & $0.1584 * * *$ & 0.1668 **** \\
\hline & & $(0.0294)$ & $(0.0339)$ & & $(0.0033)$ & $(0.0041)$ & & $(0.0033)$ & $(0.0041)$ \\
\hline \multirow{2}{*}{ Job type } & & $0.4867 * * *$ & $0.4865^{* * *}$ & & -0.00317 & $-0.003^{* * *}$ & & $-0.027 * * *$ & $-0.0265 * * *$ \\
\hline & & $(0.0176)$ & $(0.0204)$ & & $(0.0019)$ & $(0.00231)$ & & $(0.0020)$ & $(0.00242)$ \\
\hline \multirow{2}{*}{ Firm type } & & -0.265 & $-0.2678 * * *$ & & $-0.212 * * *$ & $-0.2158 * * *$ & & $-0.1111 * * *$ & $-0.1065^{* * *}$ \\
\hline & & $(0.0503)$ & $(0.0583)$ & & $(0.0055)$ & $(0.0061)$ & & $(0.0055)$ & $(0.0067)$ \\
\hline \multirow{2}{*}{ Work type } & & $-1.4006 * * *$ & $-1.336^{* * *}$ & & 0.002372 & $0.00759 * * *$ & & $0.0201 * * *$ & $0.014 * * *$ \\
\hline & & $(0.0336)$ & $(0.03899)$ & & $(0.0035)$ & $(0.00424)$ & & $(0.0038)$ & $(0.00464)$ \\
\hline \multirow{2}{*}{ _cons } & $35.317 * * *$ & $45.173^{* * *}$ & $45.989 * * *$ & 0.00511 & -0.1681 & -0.034 & 0.0621 & $-1.7843 * * *$ & $-1.88 * * *$ \\
\hline & (1.244) & (1.7439) & (1.79870 & $(0.0991)$ & $(0.16772)$ & $(0.1785)$ & $(0.1229)$ & $(0.2274)$ & $(0.227)$ \\
\hline Income level FE & YES & YES & YES & YES & YES & YES & YES & YES & YES \\
\hline Edu Years FE & YES & YES & YES & YES & YES & YES & YES & YES & YES \\
\hline Year FE & YES & YES & YES & YES & YES & YES & YES & YES & YES \\
\hline City FE & YES & YES & YES & YES & YES & YES & YES & YES & YES \\
\hline$R^{2}$ & 0.578 & 0.5714 & 0.6075 & 0.0279 & 0.0785 & 0.076 & 0.1643 & 0.2397 & 0.2378 \\
\hline$N$ & 720900 & 560998 & 400439 & 720900 & 560438 & 399786 & 516337 & 392601 & 262548 \\
\hline
\end{tabular}


Notes: Robust standard errors in parentheses, ***,**,* indicate significance at 1,5 and $10 \%$. The $\mathrm{R}^{2}$ in regression SMI and HP were Pseudo $\mathrm{R}^{2}$.All specifications have year fixed effects, city fixed effects, and individual's income-level and education-level controls, clustered at the individual level. Education and income may effects on the economic behaviors; hence, we control the education and income in all regressions. Columns (1) (2) (4) (5) (7) (8) use all sample to estimate regression for those who whether accept the health education; Colum's (3) (6) (9) use accept health sample to estimate regression for those who whether accept higher health education level.

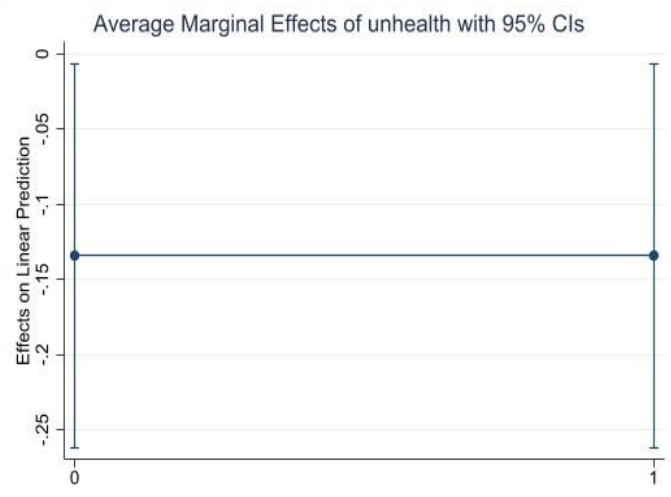

a) Accept Health education and None-acceptation

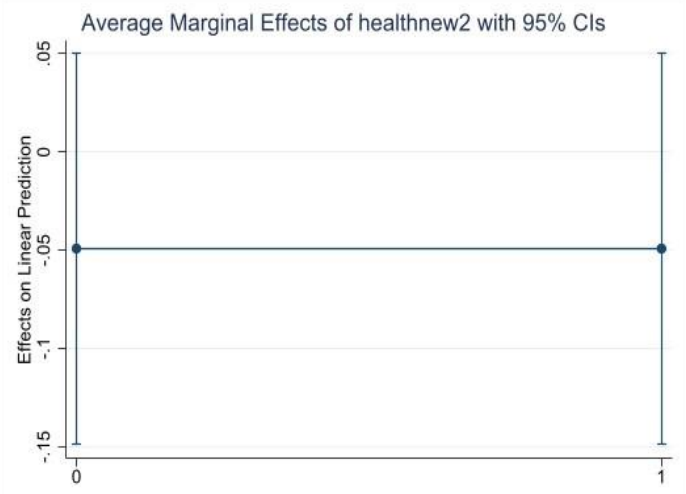

b) Lower health education and higher health education

FIGURE 5 Average marginal effects of health education on saving rates

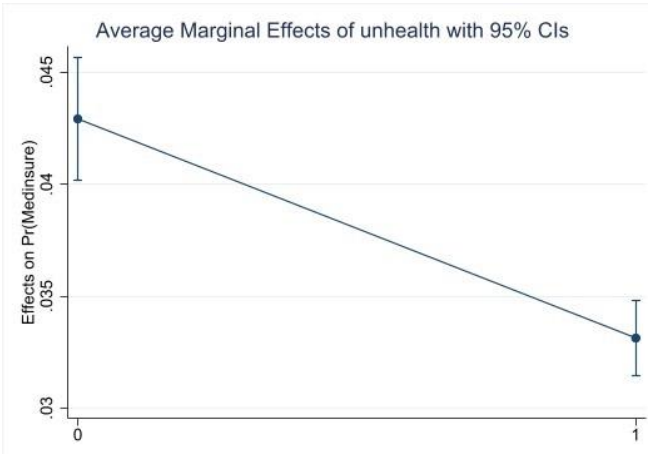

a) Accept Health education and None-acception

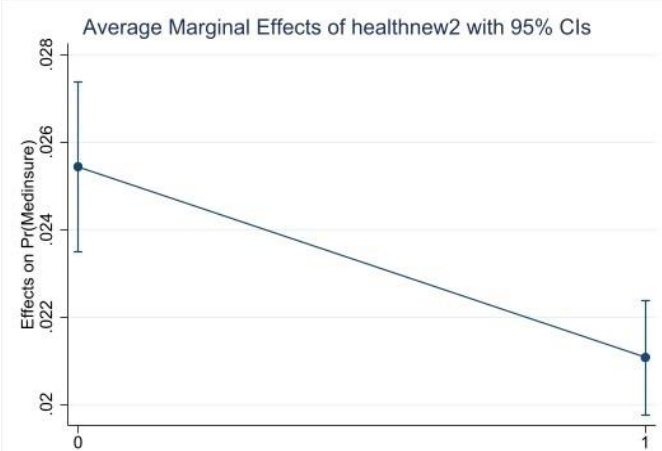

b) Lower health education and higher health education FIGURE 6 average marginal effects of health education on social medical insurance

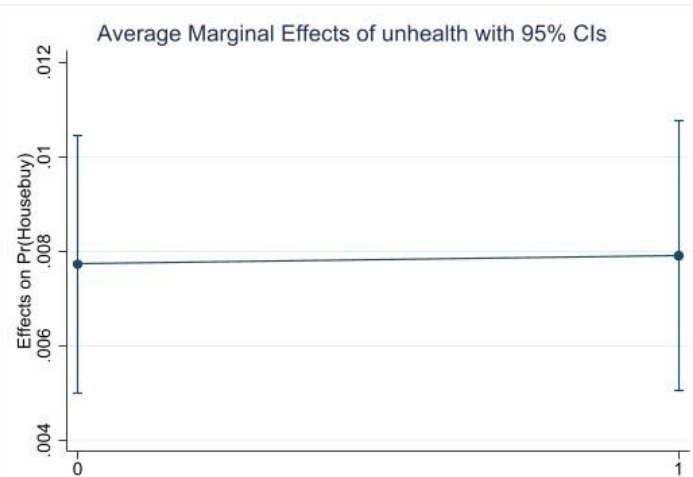

a) Accept Health education and None-acception

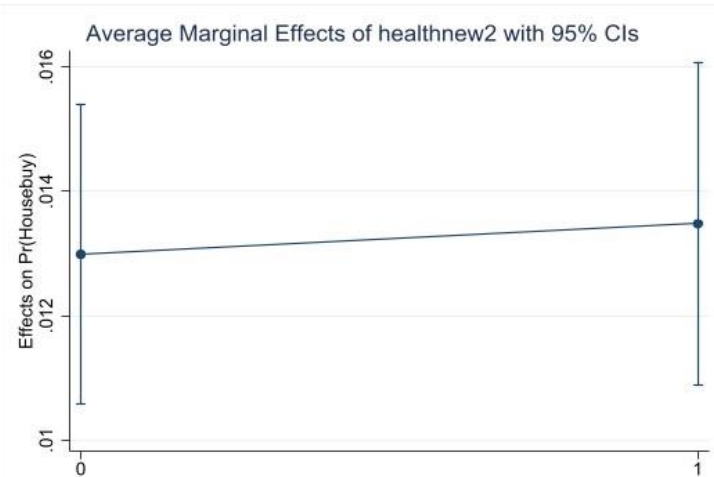

b) Lower health education and higher health education FIGURE 7: Average marginal effects of health education on house puchasing

\subsection{Casual Effects of Health Education}

\subsubsection{Interpreting instrumental variable estimate}

We account for the possibly endogenous variable between health education and economic behavior. 
Because the causal effects and sample selection bias may cause in endogenous, so we ought to test. We solve the potential endogenous through the methods with the ERM model. We adopt the index of "whether establish health documents in village" as an instrumental variable. The reason is that village where establish the health documents reflects the village and individuals health education level, however not directly affect the individual economic behaviors.

In terms of savings rates, we estimate the basic regression to alleviate the endogenous by the ERM model. Table 3 represents the instrument variable estimation results. Model (1) shows the estimation result of the first choice node, and model (2) shows the second choice node. The evaluation with the correlation error implies that the health education and saving rates survived endogenously; Wald chi2 for identifying weak instrumental variables are critical values more significant than the $10 \%$ test level, which means the instrumental variables selected in this paper are effective. The IV estimation is significantly negative in all samples, and model (2) further implies that the continuous health education values have significant effects on accepting health education samples. Table 4 represents the instruments variable estimation on social medical insurance and purchasing house. Model (1) and (2) show the estimation result of the social medical insurance instruments variable regression and Model (3) and (4) show the house purchasing instruments variable estimation. The correlation error all significant than the 10\%, which means the ERM model is an effective method to decrease endogenous issues. The weak instrumental variable test significantly rejects the null hypothesis, which further proves that the instrumental variables selected in this paper are valid.

In summary, the estimation results also confirm the influence of health education on migrant is saving rates, participation in medical social security, and purchasing houses.

Table 3 ERM Model of Health Education and Saving Rates (OLS)

\begin{tabular}{|c|c|c|c|c|}
\hline & \multicolumn{2}{|c|}{$\begin{array}{l}\text { SR } \\
\text { (1) }\end{array}$} & \multicolumn{2}{|c|}{$\begin{array}{l}\text { SR } \\
(2)\end{array}$} \\
\hline $\mathrm{HE}$ & $\times$ & $\begin{array}{c}-40.59 * * * \\
(0.396)\end{array}$ & $\times$ & $\begin{array}{c}-38.76 \\
(0.75015)\end{array}$ \\
\hline Health Documents & $\begin{array}{c}0.1684 * * * \\
(0.0009)\end{array}$ & $x$ & $\begin{array}{c}0.1541 * * * \\
(0.0016)\end{array}$ & $\times$ \\
\hline Control & YES & YES & YES & YES \\
\hline Year FE & YES & YES & YES & YES \\
\hline City FE & YES & YES & YES & YES \\
\hline Wald chi $^{2}$ & $x$ & $7307.8^{* * *}$ & $x$ & $2670.9 * * *$ \\
\hline Corr error & $x$ & $\begin{array}{c}0.4691 * * * \\
(0.0046)\end{array}$ & $x$ & $\begin{array}{c}0.6095 * * * \\
(0.00681)\end{array}$ \\
\hline$N$ & 560998 & 560998 & 400439 & 400439 \\
\hline
\end{tabular}

Notes: Standard errors in parentheses, $* p<0.10, * * p<0.05, * * * p<0.01$; The values in brackets in the cluster individual error. All specifications have year fixed effects, city fixed effects, and individual's income-level and education-level controls, clustered at the individual level. In the regressions, we control the variables of age, ages, gender, married, out year, ttlfam, outfit, job type, firm type and work type of migrant.

Table 4 ERM Model Returns to Health Education on Social Medical Insurance and Purchasing House (eoprobit)

SMI SMI




\begin{tabular}{|c|c|c|c|c|}
\hline HE & $\times$ & $\begin{array}{c}0.966 * * * \\
(0.024)\end{array}$ & $\times$ & $\begin{array}{c}0.7523 * * * \\
(0.028)\end{array}$ \\
\hline Health Documents & $\begin{array}{c}0.171 * * * \\
(0.0008)\end{array}$ & $x$ & $\begin{array}{l}0.1641 * * * \\
(0.01314)\end{array}$ & $x$ \\
\hline Wald chi2 & $x$ & $1553.56 * * *$ & $x$ & $683.91 * * *$ \\
\hline \multirow[t]{2}{*}{ Corr error } & $x$ & $\begin{array}{c}-0.2818^{* * *} \\
(0.009)\end{array}$ & $x$ & $\begin{array}{c}-0.2877 * * * \\
(0.0013)\end{array}$ \\
\hline & \multicolumn{2}{|c|}{$\begin{array}{r}\text { HP } \\
\text { (3) }\end{array}$} & \multicolumn{2}{|c|}{$\begin{array}{r}\text { HP } \\
(4)\end{array}$} \\
\hline $\mathrm{HE}$ & $x$ & $\begin{array}{l}1.669 * * * \\
(0.0121)\end{array}$ & $x$ & $\begin{array}{l}1.806 * * * \\
(0.0095)\end{array}$ \\
\hline Health Documents & $\begin{array}{c}0.1854 * * * \\
(0.013)\end{array}$ & $x$ & $\begin{array}{c}0.13023 * * * \\
(0.018)\end{array}$ & $x$ \\
\hline Control & YES & YES & YES & YES \\
\hline Year FE & YES & YES & YES & YES \\
\hline City FE & YES & YES & YES & YES \\
\hline Wald chi2 & $x$ & $18955.18^{* * *}$ & $x$ & $36017.57 * * *$ \\
\hline Corr error & $x$ & $\begin{array}{c}-0.676^{* * *} \\
(0.0051)\end{array}$ & $x$ & $\begin{array}{c}-0.8052 * * * \\
(0.00406)\end{array}$ \\
\hline$N$ & 560998 & 560998 & 400439 & 400439 \\
\hline
\end{tabular}

Notes: Standard errors in parentheses, $* p<0.10, * * p<0.05, * * *<0.01$; In the regressions, we control the variables of age, agesq, gender, married, out year, ttlfam, outfam, job type, firm type and work type of migrant. All specifications have year fixed effects, city fixed effects, and individual's income-level and education-level controls, clustered at the individual level.

\subsubsection{The estimated average causal effect of health education choices}

This section we move beyond OLS and Probit method to analysis the casual effects of health education returns on economic behaviors. According to the equal, we show the evidence about average treatment effects through health education choice node in Table 5. The estimate average casual effects are lower than the OLS and Probit regression in Table 4.In terms of average treatment effects on saving rates, we find that the returns to health education on saving rates shape invert $\mathrm{U}$, the effects was larger negative effects for those who acquisition the health education in first choice ,reaching $12.8 \%$. Contrast, it is not significance effects between lower health education and higher health education. For social medical insurance, the average treatment effects more likely positive effects on first choice node, reaching 3.97\%. Lastly, we note that average treatment effects of purchasing house increasing significance as the health education increased by $2.97 \%$.

The estimate of average treatment effects and total treatment effects are similar as OLS and Probit regression in Table 3. However, the coefficient with health education in the OLS and Probit regression model is a weighted average with potentially negative weights| across the treatment effect parameter. 
Table 5 Decomposing Treatment Effects of Health Education

\begin{tabular}{|c|c|c|c|c|c|c|c|c|c|}
\hline \multirow[b]{3}{*}{$\begin{array}{c}\text { Treatments } \\
\text { Effects }\end{array}$} & \multirow{2}{*}{\multicolumn{3}{|c|}{$\begin{array}{c}\text { Panel (A) } \\
\text { SR }\end{array}$}} & \multirow{2}{*}{\multicolumn{3}{|c|}{$\begin{array}{c}\text { Panel(B) } \\
\text { SMI }\end{array}$}} & \multirow{2}{*}{\multicolumn{3}{|c|}{$\begin{array}{c}\text { Panel(C) } \\
\text { HP }\end{array}$}} \\
\hline & & & & & & & & & \\
\hline & Health Education & $\begin{array}{c}\text { Lower Health } \\
\text { Education }\end{array}$ & $\begin{array}{c}\text { Higher Health } \\
\text { Education }\end{array}$ & Health Education & $\begin{array}{c}\text { Lower Health } \\
\text { Education }\end{array}$ & $\begin{array}{c}\text { Higher Health } \\
\text { Education }\end{array}$ & Health Education & $\begin{array}{c}\text { Lower Health } \\
\text { Education }\end{array}$ & $\begin{array}{c}\text { Higher Health } \\
\text { Education }\end{array}$ \\
\hline \multirow{2}{*}{ ATE } & -0.128 & -0.131 & -0.0158 & 0.0397 & 0.0273 & 0.0288 & 0.0122 & 0.0212 & 0.0297 \\
\hline & {$[0.0072]$} & {$[0.21]$} & {$[0.0036]$} & {$[0.00034]$} & [0.00119] & {$[0.00067]$} & {$[0.007]$} & {$[0.0031]$} & {$[0.0065]$} \\
\hline \multirow{2}{*}{$\mathrm{TT}$} & -0.128 & 0.015 & -0.0183 & 0.041 & 0.024 & 0.032 & 0.0112 & 0.027 & 0.0311 \\
\hline & {$[0.0052]$} & {$[0.07]$} & {$[0.0027]$} & {$[0.00016]$} & {$[0.0021]$} & [0.0097] & [0.009] & {$[0.012]$} & [0.0097] \\
\hline \multirow{2}{*}{ AMTE } & -0.1343 & -0.049 & -0.049 & 0.03312 & 0.02544 & 0.02106 & 0.007903 & 0.01298 & 0.0134 \\
\hline & {$[0.0651]$} & {$[0.0507]$} & {$[0.0507]$} & {$[0.00086]$} & [0.0009] & {$[0.0027]$} & {$[0.00145]$} & [0.00123] & [0.0132] \\
\hline \multirow{2}{*}{ IV } & -0.212 & 0.012 & -0.371 & 0.012 & 0.023 & 0.144 & 0.02536 & 0.02596 & 0.0279 \\
\hline & {$[0.017]$} & [0.0011] & {$[0.021]$} & {$[0.00021]$} & {$[0.0014]$} & {$[0.0196]$} & {$[0.0039]$} & {$[0.033]$} & {$[0.00382]$} \\
\hline $\mathrm{N}$ & 608281 & 402215 & 190653 & 608281 & 402215 & 190653 & 608281 & 40215 & 190653 \\
\hline
\end{tabular}

Note: Standard error at the individual level in brackets; The TT row reports the average effect for chose higher health education, AMTE presents the continuous returns with choosing the health education in node. IV represents the health education instruments estimated treatment effect after controlling for education; income; years; city and other control variables. The values in brackets is robust error. 


\subsection{Heterogeneity Treatment Effects}

\subsubsection{Intergeneration heterogeneity}

Account for the heterogeneity in the previous generation and young generating ${ }^{9}$ on health educational choice. The heterogeneity treatments effects(SM) to further evaluate three propositions in the paper(Yu Xie, Jennie E. Brand,2012).Table 6 and Table 7 report the results about intergeneration heterogeneity treatment effects with the stratification-multilevel method (SM), including first health educational choice nodes and second health educational choice nodes, respectively.

Table 6 presents the propensity score strata between accept health education previous generation and young generation. We find the frequency count increase with the propensity score for those who accept health education previous generation, whereas the direction of frequency count opposite to the propensity score for the young generation. The possible explanation is that the young generation, mostly born after 1980, prefers to enjoy current life and have safety beliefs in the prospect. However, the previous generation mostly has children to raise and needs to spend on family life and children's education, making them more unsafe in future life. Those results verify the proposition in the paper again. In terms of participating social medical insurance, new generation has a more significant effect of accept health education on participating in social medical insurance. One possible explanation is that the new generation of the migrant has a higher demand for public services such as medical care and is relatively more knowledgeable in health education and has a higher awareness of insurance participation than the previous generation of migrants. It appears that the similar results in house purchasing. One possible explanation is that previous generations expected an abundance of savings, so they did not purchase houses. Hence, they incline to the relatively stable investment. Table 7 report the propensity score strata between higher health education previous generation and young generation. In contrast, the young generation with higher education has more willingness to save and participate in social medical insurance than the previous generation. It means the young generation has an awareness of pressure by aging social. Hence, they seem healthy as a continuous investment. Figure 8; Figure 9; and Figure 10 reports health educational heterogeneity outcomes. We find that improving health education to stimulate domestic consumption is not wise for those young generations with higher health education.

Table 6 Heterogeneous Treatments Effects of intergeneration on First Choice Nodes (SM)

\begin{tabular}{|c|c|c|c|c|c|c|}
\hline & $\begin{array}{c}\text { SR } \\
\text { (Previous } \\
\text { Generation) }\end{array}$ & $\begin{array}{c}\text { SR } \\
\text { (Young } \\
\text { Generation) }\end{array}$ & $\begin{array}{c}\text { SMI } \\
\text { (Previous } \\
\text { Generation) }\end{array}$ & $\begin{array}{c}\text { SMI } \\
\text { (Young } \\
\text { Generation) }\end{array}$ & $\begin{array}{c}\text { HP } \\
\text { (Previous } \\
\text { Generation) }\end{array}$ & $\begin{array}{c}\text { HP } \\
\text { (Young } \\
\text { Generation) }\end{array}$ \\
\hline \multirow[t]{2}{*}{ Stratum 4} & -6.348 & $-8.97 * *$ & 0.1064 & 0.006 & -0.0333 & 0.094 \\
\hline & (4.338) & $(4.532)$ & $(0.072)$ & $(0.0792)$ & $(0.086)$ & $(0.0921)$ \\
\hline \multirow[t]{2}{*}{ Stratum 5} & $-7.818 * * *$ & $-4.266 * * *$ & 0.0341 & $0.0908^{* * *}$ & $0.0541^{*}$ & $0.058^{*}$ \\
\hline & $(1.821)$ & (1.5788) & $(0.0246)$ & $(0.0233)$ & $(0.0315)$ & $(0.024)$ \\
\hline \multirow[t]{2}{*}{ Stratum 6} & $-8.388 * * *$ & $-8.6132 * * *$ & $0.0506 * *$ & $0.0952 * * *$ & $0.1182 * * *$ & $0.0453 * *$ \\
\hline & (1.4628) & (1.1055) & $(0.018)$ & $(0.0153)$ & $(0.0241)$ & $(0.0157)$ \\
\hline
\end{tabular}

\footnotetext{
${ }^{9}$ Base on the characteristics of the Chinese migrant, aged between 15 and 35 years old as the new generation of migrant (Young generation=1), aged between 35 and 59 years old defined as the previous generation of migrant (Young generation $=0$ ) .
} 


\begin{tabular}{|c|c|c|c|c|c|c|}
\hline \multirow[t]{2}{*}{ Stratum 7} & $-6.156 * * *$ & $-5.1753 * * *$ & $0.0466^{* * *}$ & $0.0461 * * *$ & $0.06422 * * *$ & 0.02142 \\
\hline & $(1.061)$ & (1.0402) & $(0.0122)$ & $(0.0131)$ & $(0.0176)$ & $(0.0156)$ \\
\hline \multirow[t]{2}{*}{ Stratum 8} & $-6.62 * * *$ & $-4.5862 * * *$ & $0.0396^{* * *}$ & $0.0744 * * *$ & $0.0519 * * *$ & $0.0212 * * *$ \\
\hline & $(0.4451)$ & $(0.3554)$ & $(0.05)$ & $(0.0044)$ & $(0.0073)$ & $(0.0044)$ \\
\hline \multirow[t]{2}{*}{ Stratum 9} & $-6.06^{* * *}$ & $-5.0671 * * *$ & $0.0485^{* * *}$ & $0.064 * * *$ & $0.0297 * * *$ & $0.03599^{* * *}$ \\
\hline & $(0.6484)$ & $(0.6926)$ & $(0.0068)$ & $(0.0081)$ & $(0.0105)$ & $(0.0101)$ \\
\hline Stratum & $-6.82^{* * *}$ & $-5.221 * * *$ & $0.0468 * * *$ & $0.0701 * * *$ & $0.0297 * *$ & $0.0381 * * *$ \\
\hline 10 & $(0.5909)$ & $(0.554)$ & $(0.00621)$ & $(0.0068)$ & $(0.0105)$ & $(0.00808)$ \\
\hline Stratum & $-6.61 * * *$ & $-4.762 * * *$ & $0.05183^{* * *}$ & $0.077 * * *$ & $0.0507 * * *$ & $0.03167 * * *$ \\
\hline 11 & $(0.3745)$ & $(0.3098)$ & $(0.004)$ & $(0.00387)$ & $(0.0065)$ & $(0.00428)$ \\
\hline Stratum & $-6.395 * * *$ & $-5.893 * * *$ & $0.0458^{* * *}$ & $0.0621^{* * *}$ & $0.0381^{* * * *}$ & $0.03786 * * *$ \\
\hline 12 & $(0.335)$ & $(0.362)$ & $(0.0035)$ & $(0.00419)$ & $(0.0058)$ & $(0.00596)$ \\
\hline Stratum & $-6.901 * * *$ & $-5.08^{* * *}$ & $0.044 * * *$ & $0.0583 * * *$ & $0.0402 * * *$ & $0.0275^{* * *}$ \\
\hline 13 & $(0.4516)$ & $(0.4508)$ & $(0.0049)$ & $(0.00516)$ & $(0.0079)$ & $(0.0069)$ \\
\hline Stratum & $-5.649 * * *$ & $-4.79 * * *$ & $0.0599 * * *$ & $0.0727 * * *$ & $0.034 * * *$ & $0.0424 * * *$ \\
\hline 14 & $(0.4292)$ & $(0.3919)$ & $(0.0047)$ & $(0.00473)$ & $(0.0078)$ & $(0.0064)$ \\
\hline Stratum & $-6.2519 * * *$ & $-4.85^{* * *}$ & $0.0539^{* * *}$ & $0.0474 * * *$ & $0.0515^{* * *}$ & $0.0294 * * *$ \\
\hline 15 & $(0.3268)$ & $(0.3318)$ & $(0.0036)$ & $(0.00375)$ & $(0.0061)$ & $(0.00596)$ \\
\hline Stratum & $-5.538 * * *$ & $-4.6^{* * *}$ & $0.0654 * * *$ & $0.0421 * * *$ & $0.0331 * * *$ & 0.0124 \\
\hline 16 & $(0.575)$ & $(0.5493)$ & $(0.0062)$ & $(0.00589)$ & $(0.0108)$ & $(0.00919)$ \\
\hline Stratum & $-5.915 * * *$ & $-3.95^{* * *}$ & $0.0363 * * *$ & $0.0477 * * *$ & $0.0436^{* *}$ & 0.0201 \\
\hline 17 & $(0.8336)$ & $(0.7661)$ & $(0.009)$ & $(0.00856)$ & $(0.0159)$ & $(0.0135)$ \\
\hline Stratum & $-5.666 * * *$ & $-5.078 * * *$ & $0.039 * * *$ & $0.0497 * * *$ & $0.034^{*}$ & $0.0359 * * *$ \\
\hline 18 & $(0.8367)$ & $(0.7849)$ & $(0.0094)$ & $(0.00842)$ & $(0.0163)$ & $(0.0149)$ \\
\hline Stratum & $-5.588 * * *$ & $-4.5515^{* * *}$ & $0.0506^{* * *}$ & $0.0434 * * *$ & $0.0319 * * *$ & $0.0281 * * *$ \\
\hline 19 & $(0.5207)$ & $(0.4348)$ & $(0.005)$ & $(0.00466)$ & $(0.0104)$ & $(0.0084)$ \\
\hline Stratum & $-4.65 * * *$ & $-4.3199 * * *$ & $0.0332 * *$ & $0.0253 * * *$ & $0.0594 * *$ & 0.0121 \\
\hline 20 & $(1.103)$ & $(0.752)$ & $(0.0107)$ & $(0.0066)$ & $(0.0236)$ & $(0.0152)$ \\
\hline Stratum & $-5.4365 * * *$ & $-5.224 * * *$ & 0.0226 & $0.0227^{*}$ & $0.1322 * * *$ & $0.0725^{* *}$ \\
\hline 21 & $(1.8642)$ & $(1.227)$ & $(0.017)$ & $(0.0102)$ & $(0.0401)$ & $(0.0262)$ \\
\hline Stratum & -2.3099 & $-6.95^{* *}$ & 0.0354 & 0.0253 & -0.0233 & $0.0827^{*}$ \\
\hline 22 & (3.4403) & $(2.255)$ & $(0.0254)$ & $(0.0172)$ & $(0.072)$ & $(0.047)$ \\
\hline Stratum & $-10.91 * * *$ & -4.91 & 0.0524 & -0.00274 & -0.08 & $0.123 *$ \\
\hline 23 & (5.37) & (3.33) & $(0.0438)$ & $(0.0232)$ & $(0.114)$ & $(0.0691)$ \\
\hline Stratum & -7.39 & -2.015 & -0.0126 & -0.0141 & 0.0737 & -0.1489 \\
\hline 24 & $(9.445)$ & (6.464) & $(0.0399)$ & $(0.0317)$ & $(0.194)$ & $(0.153)$ \\
\hline \multirow[t]{2}{*}{ Slope } & $0.113^{* *}$ & 0.0471 & $-0.00377 * * *$ & 0.00297 & $-0.0011 * * *$ & 0.000102 \\
\hline & $(.0395)$ & $(.0333238)$ & $(0.00036)$ & $(.0004265)$ & $(0.00072)$ & $(0.00054)$ \\
\hline cons & $-7.732 * * *$ & $-5.565^{* *}$ & $0.1096^{* * *}$ & $045226 * * *$ & $0.058 * * *$ & $0.0292 * * *$ \\
\hline
\end{tabular}

Note: Standard errors in bracket, $* p<0.10,{ }^{* *} p<0.05,{ }^{* * *} p<0.01$; In the regressions, we control the variables of gender, married, out year, ttlfam, outfam, job type, firm type and work type of migrant. All specifications have year fixed effects, city fixed effects, and individual's income-level and education-level controls, clustered at the individual level. Previous generation indicates immigrants who accept the health education; young generation indicates immigrates who accept health education. Propensity scores were generated by a Probit and OLS regression model .Propensity score strata were balanced such that mean values of covariates did not significantly differ 
between previous generation and young generation.

Table 7 Heterogeneous Treatments Effects of intergeneration on Second Choice Nodes (SM)

\begin{tabular}{|c|c|c|c|c|c|c|}
\hline & $\begin{array}{c}\text { SR } \\
\text { (Previous } \\
\text { Generation) }\end{array}$ & $\begin{array}{c}\text { SR } \\
\text { (Young } \\
\text { Generation) }\end{array}$ & $\begin{array}{c}\text { SMI } \\
\text { (Previous } \\
\text { Generation) }\end{array}$ & $\begin{array}{c}\text { SMI } \\
\text { (Young } \\
\text { Generation) }\end{array}$ & $\begin{array}{c}\text { HP } \\
\text { (Previous } \\
\text { Generation) }\end{array}$ & $\begin{array}{c}\text { HP } \\
\text { (Young } \\
\text { Generation) }\end{array}$ \\
\hline \multirow[t]{2}{*}{ Stratum 2} & 3.927 & 0.548 & 0.051 & $0.089 * * *$ & $0.096^{* *}$ & 0.021 \\
\hline & $(2.5335)$ & (1.9020) & $(0.0321)$ & $(0.0283)$ & $(0.0431)$ & $(0.0242)$ \\
\hline \multirow[t]{2}{*}{ Stratum 3} & -0.927 & -0.776 & $0.032 * * *$ & $0.073 * * *$ & $0.056^{* * *}$ & $0.056^{* * *}$ \\
\hline & $(0.7613)$ & $(0.7019)$ & $(0.0089)$ & $(0.0089)$ & $(0.0122)$ & $(0.0104)$ \\
\hline \multirow[t]{2}{*}{ Stratum 4} & $-1.561 *$ & 0.045 & $0.045 * * *$ & $0.065 * * *$ & $0.076^{* * *}$ & $0.046^{* * *}$ \\
\hline & $(0.8752)$ & $(0.6070)$ & $(0.0106)$ & $(0.0087)$ & $(0.0164)$ & $(0.0079)$ \\
\hline \multirow[t]{2}{*}{ Stratum 5} & 0.738 & 0.142 & $0.038 * * *$ & $0.051 * * *$ & $0.059 * * *$ & $0.053 * * *$ \\
\hline & $(0.5799)$ & $(0.4225)$ & $(0.0071)$ & $(0.0060)$ & $(0.0104)$ & $(0.0064)$ \\
\hline \multirow[t]{2}{*}{ Stratum 6} & $0.780^{*}$ & $2.235^{* * *}$ & $0.039 * * *$ & $0.045^{* * *}$ & $0.051 * * *$ & $0.029 * * *$ \\
\hline & $(0.4258)$ & $(0.3435)$ & $(0.0044)$ & $(0.0039)$ & $(0.0073)$ & $(0.005)$ \\
\hline \multirow[t]{2}{*}{ Stratum 7} & -0.201 & $1.140 * * *$ & $0.042 * * *$ & $0.043 * * *$ & $0.061 * * *$ & $0.037 * * *$ \\
\hline & $(0.3677)$ & $(0.3064)$ & $(0.0037)$ & $(0.0034)$ & $(0.0063)$ & $(0.0049)$ \\
\hline \multirow[t]{2}{*}{ Stratum 8} & 0.543 & 0.663 & $0.029 * * *$ & $0.033 * * *$ & $0.074 * * *$ & $0.073 * * *$ \\
\hline & $(0.4991)$ & $(0.4842)$ & $(0.0054)$ & $(0.0052)$ & $(0.0091)$ & $(0.0084)$ \\
\hline \multirow[t]{2}{*}{ Stratum 9} & -0.569 & $1.229 * * *$ & $0.031 * * *$ & $0.034 * * *$ & $0.058 * * *$ & $0.040 * * *$ \\
\hline & $(0.4349)$ & $(0.4348)$ & $(0.0047)$ & $(0.0051)$ & $(0.0083)$ & $(0.0081)$ \\
\hline \multirow[t]{2}{*}{ Stratum 10} & 0.466 & 0.388 & $0.037 * * *$ & $0.054 * * *$ & $0.046^{* * *}$ & $0.034 * * *$ \\
\hline & $(0.529)$ & $(0.4041)$ & $(0.0061)$ & $(0.0054)$ & $(0.0107)$ & $(0.0065)$ \\
\hline \multirow[t]{2}{*}{ Stratum 11} & -0.594 & $0.751^{*}$ & $0.041 * * *$ & $0.029 * * *$ & $0.050 * * *$ & $0.058 * * *$ \\
\hline & $(0.3952)$ & $(0.4170)$ & $(0.0045)$ & $(0.0049)$ & $(0.0081)$ & $(0.0082)$ \\
\hline \multirow[t]{2}{*}{ Stratum 12} & 0.380 & $0.902 * * *$ & $0.032 * * *$ & $0.039 * * *$ & $0.037 * * *$ & $0.028 * * *$ \\
\hline & $(0.2766)$ & $(0.2586)$ & $(0.0030)$ & $(0.0032)$ & $(0.0055)$ & $(0.0048)$ \\
\hline \multirow[t]{2}{*}{ Stratum 13} & $0.790^{* *}$ & $0.603^{*}$ & $0.029 * * *$ & $0.027 * * *$ & $0.026 * * *$ & $0.036^{* * *}$ \\
\hline & $(0.3286)$ & $(0.3458)$ & $(0.0037)$ & $(0.0040)$ & $(0.0066)$ & $(0.0066)$ \\
\hline \multirow[t]{2}{*}{ Stratum 14} & 0.211 & $1.125^{* * *}$ & $0.031 * * *$ & $0.031 * * *$ & $0.036^{* * *}$ & $0.019^{* *}$ \\
\hline & $(0.3720)$ & $(0.3665)$ & $(0.0041)$ & $(0.0042)$ & $(0.0082)$ & $(0.0078)$ \\
\hline \multirow[t]{2}{*}{ Stratum 15} & $1.779 * * *$ & $1.900^{* * *}$ & $0.030 * * *$ & $0.034 * * *$ & $0.053 * * *$ & $0.030 * * *$ \\
\hline & $(0.3547)$ & $(0.3562)$ & $(0.0039)$ & $(0.0039)$ & $(0.0078)$ & $(0.0070)$ \\
\hline \multirow[t]{2}{*}{ Stratum 16} & $1.708 * * *$ & $1.892 * * *$ & $0.025 * * *$ & $0.033 * * *$ & $0.057 * * *$ & $0.033 * * *$ \\
\hline & $(0.5957)$ & $(0.4391)$ & $(0.0060)$ & $(0.0044)$ & $(0.0131)$ & $(0.0088)$ \\
\hline \multirow[t]{2}{*}{ Stratum 17} & 0.743 & $1.478^{* * *}$ & $0.023 * * *$ & $0.017 * * *$ & $0.037 * * *$ & $0.028 * * *$ \\
\hline & $(0.5329)$ & $(0.4378)$ & $(0.0055)$ & $(0.0044)$ & $(0.0121)$ & $(0.0101)$ \\
\hline \multirow[t]{2}{*}{ Stratum 18} & -0.447 & 1.409 & 0.009 & 0.015 & $0.098 * * *$ & 0.033 \\
\hline & $(1.0905)$ & $(1.0455)$ & $(0.0134)$ & $(0.0112)$ & $(0.0260)$ & $(0.0239)$ \\
\hline \multirow[t]{2}{*}{ Stratum 19} & $2.650^{*}$ & $3.725^{* * *}$ & 0.008 & 0.013 & 0.048 & -0.007 \\
\hline & $(1.4837)$ & $(1.1517)$ & $(0.0125)$ & $(0.0085)$ & $(0.0312)$ & $(0.0219)$ \\
\hline \multirow[t]{2}{*}{ Stratum 20} & $5.439^{* *}$ & $2.927 * * *$ & 0.010 & 0.007 & 0.058 & -0.002 \\
\hline & $(01.8876)$ & (1.0940) & $(0.022)$ & $(0.0098)$ & $(0.0422)$ & $(0.0193)$ \\
\hline Stratum 21 & 1.282 & $2.891 * * *$ & $0.018 * *$ & $0.024 * * *$ & $0.040 * *$ & 0.011 \\
\hline
\end{tabular}




\begin{tabular}{ccccccc} 
& $(0.8743)$ & $(0.6161)$ & $(0.0073)$ & $(0.0051)$ & $(0.0195)$ & $(0.0138)$ \\
Stratum 22 & -0.652 & $4.886^{* * *}$ & -0.011 & $0.026^{*}$ & -0.073 & -0.003 \\
& $(2.3256)$ & $(1.7789)$ & $(0.0215)$ & $(0.0154)$ & $(0.0547)$ & $(0.0399)$ \\
Stratum 23 & -1.700 & -1.162 & 0.034 & 0.022 & $0.118^{*}$ & $0.082^{*}$ \\
& $(2.9403)$ & $(1.9682)$ & $(0.0239)$ & $(0.0181)$ & $(0.0666)$ & $(0.0439)$ \\
Stratum 24 & 3.093 & 1.017 & -0.0015 & 0.015 & $0.104^{* *}$ & 0.024 \\
& $(2.270)$ & $(1.8788)$ & $(0.0157)$ & $(0.0139)$ & $(0.0484)$ & $(0.0442)$ \\
Slope & $0.105^{* * *}$ & $0.085^{* * *}$ & $-0.001 * * *$ & $-0.002^{* * *}$ & $-0.002^{* * *}$ & $-0.002^{* * *}$ \\
& $(0.0273)$ & $(0.0221)$ & $(0.0003)$ & $(0.0002)$ & $(0.0005)$ & $(0.0004)$ \\
cons & $-0.739^{* *}$ & 0.198 & $0.048^{* * *}$ & $0.059^{* * *}$ & $0.067 * * *$ & $0.053^{* * *}$ \\
& $(0.3273)$ & $(0.2648)$ & $(0.0034)$ & $(0.0030)$ & $(0.0060)$ & $(0.0043)$ \\
\hline
\end{tabular}

Note: Standard errors in bracket, $* p<0.10,{ }^{* *} p<0.05,{ }^{* * *} p<0.01$; In the regressions, we control the variables of gender, married, out year, ttlfam, outfam, job type, firm type and work type of migrant. All specifications have year fixed effects, city fixed effects, and individual's income-level and education-level controls, clustered at the individual level. Previous generation indicates immigrants who accept the health education; young generation indicates immigrates who accept health education. Propensity scores were generated by a Probit and OLS regression model .Propensity score strata were balanced such that mean values of covariates did not significantly differ between previous generation and young generation.

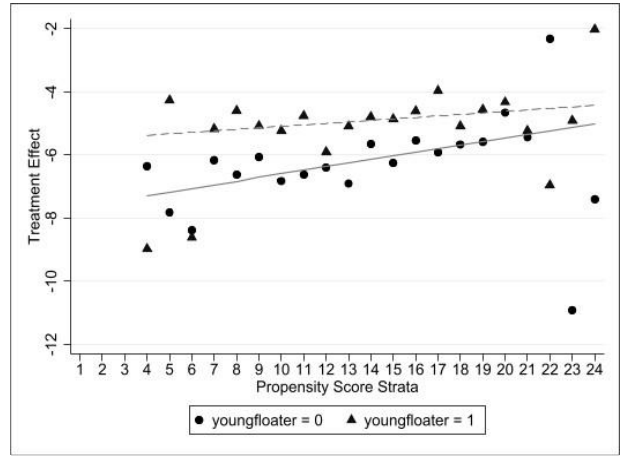

a) Accept Health education and None-acception

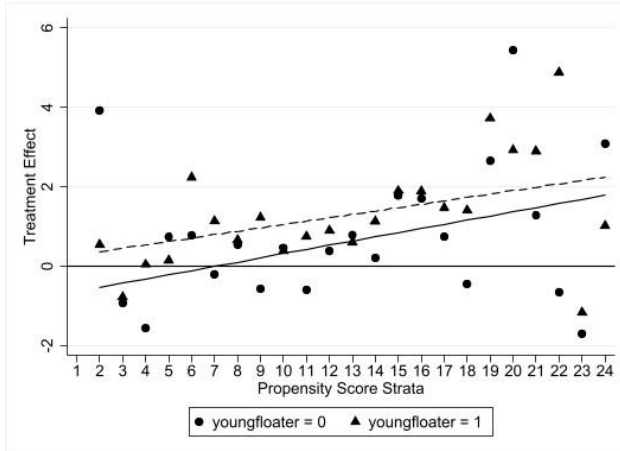

b) Lower health education and higher health education

FIGURE 8 Health education heterogeneous effects on intergeneration transmission (Saving Rates) ${ }^{10}$

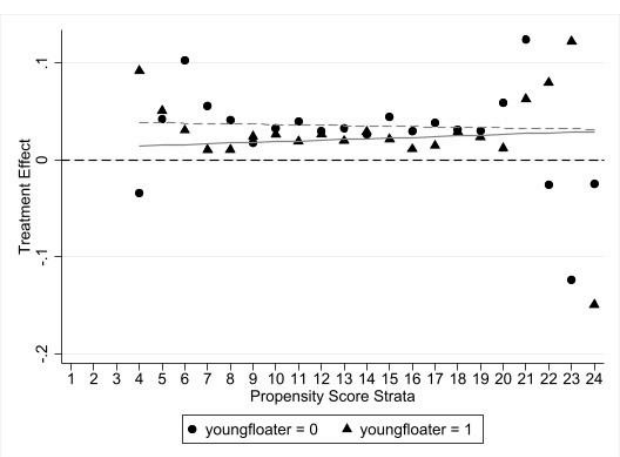

a) Accept Health education and None-acception

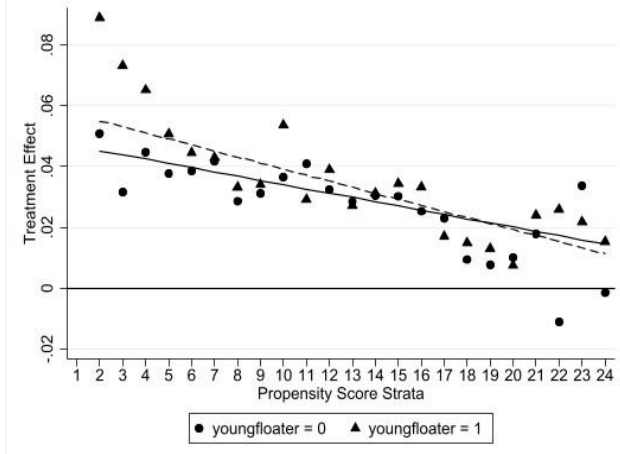

b) Lower health education and higher health education

FIGURE 9 Health education heterogeneous effects on intergeneration transmission (Social Medical Insurance)

10 We compare migrants who choose first nodes (unhealthy education and health education) and second nodes (lower health education and higher health education) same as fig 9 fig 10. 


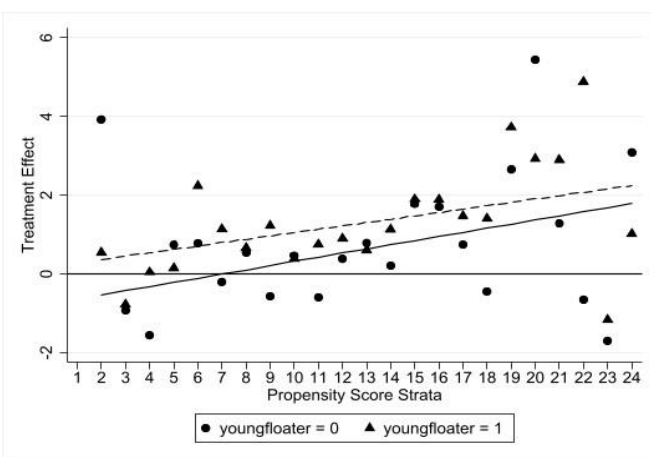

a) Accept Health education and None-acception

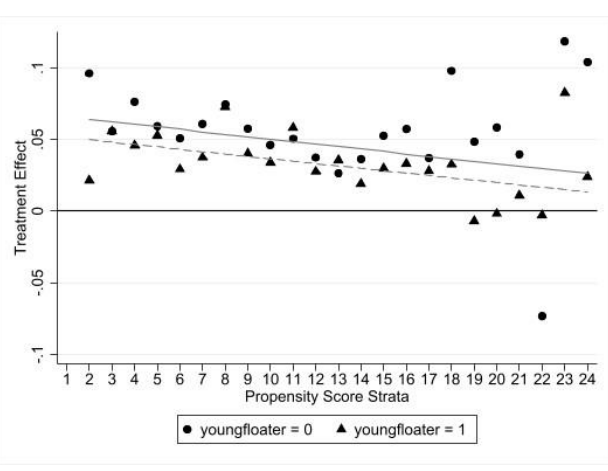

b) Accept Health education and None-accept

FIGURE 10 Health education heterogeneous effects on intergeneration transmission (House Purchasing)

\subsubsection{Urban citizenship acquisition}

Urban citizenship acquisition determines one's level of urban wage and determines one's rights to access city public service in China. Although urbanization brings the equalization of essential public health services in China, high-quality education and medical service are still distributed in eastern coastal areas. It implies that the different impacts of health education on the economic behavior of migrants are reflected in their urban citizenship acquisition, such as the type of Hukou and regional distribution of the migrant. Therefore, urban citizenship acquisition plays an essential role in immigration economic behavior. In this paper, we further explore heterogeneity in urban citizenship acquisition and rural citizenship acquisition.

Table 8 and Table 9 presents the results with urban citizenship and rural citizenship heterogeneous treatment effects all health education. We find the frequency count increase with the propensity score for those who accept health education rural citizenship. The possible explanation is rural citizenship is generally outbound for work/business. They have no long-term stable income or work at the outflow location. Hence, they need to take precautionary savings for future uncertainties. In terms of participating in medical insurance, health education improvement on the probability of participating in social health insurance is more significant for the rural citizenship relative to the urban citizenship acquisition. One possible explanation is that the public health service gap between rural and urban is reduced; rural citizenship gradually has an awareness of participating in social health insurance. At the same time, health education significantly stimulates rural citizenship the wellness of purchasing a house. One possible explanation is that purchasing a house means enjoying better public services, and dealing with children's schooling, so they have a relatively higher willingness to purchase a house than urban citizenship.

Table 9 reports higher health educational heterogeneous effects between rural and urban. Higher health education is wise for those who are having urban citizenship. Compared with urban citizenship, rural migrants have a relatively high savings rate, lower willingness to purchase housing. This means estate market bubbles and restrictions of the urban household registration system. It obliges that higher health educational rural citizenship does not wellness of purchasing a house.

Figure 11; Figue12, and Figure 13 reports that accept health education rural citizen are more likely to purchase house, participating in social medical insurance, and saving. Suppose they do not have a house in the city. In that case, they may not enjoy the same incentives as the local population in terms of medical care and education due to some household registration policies, so they need to own their own houses. However, higher health education have not positive effects on rural citizenship; one possible reason is that the estate bubble restricts them from purchasing the house, 
and the retirement issue also compelling them to have not consumption desire.

Table 8 Heterogeneous Treatments Effects of Citizenship Identify on First Choice Nodes (SM)

\begin{tabular}{|c|c|c|c|c|c|c|}
\hline & $\begin{array}{c}\text { SR } \\
\text { (Rural } \\
\text { Identification) }\end{array}$ & $\begin{array}{c}\text { SR } \\
\text { (Citizenship } \\
\text { Identification) }\end{array}$ & $\begin{array}{c}\text { SMI } \\
\text { (Rural } \\
\text { Identification) }\end{array}$ & $\begin{array}{c}\text { SMI } \\
\text { (Citizenship } \\
\text { Identification) }\end{array}$ & $\begin{array}{c}\text { HP } \\
\text { (Rural } \\
\text { Identification) }\end{array}$ & $\begin{array}{c}\text { HP } \\
\text { (Citizenship } \\
\text { Identification) }\end{array}$ \\
\hline \multirow[t]{2}{*}{ Stratum 4} & $-9.766^{* * *}$ & 3.449 & 0.024 & -0.208 & -0.001 & 0.033 \\
\hline & $(3.1820)$ & $(9.7448)$ & $(0.0522)$ & $(0.1797)$ & $(0.0625)$ & $(0.2187)$ \\
\hline \multirow[t]{2}{*}{ Stratum 5} & $-6.214 * * *$ & -1.913 & $0.080 * * *$ & -0.004 & $0.064 * * *$ & 0.049 \\
\hline & $(1.2451)$ & $(3.5324)$ & $(0.0173)$ & $(0.0628)$ & $(0.0206)$ & $(0.0669)$ \\
\hline \multirow[t]{2}{*}{ Stratum 6} & $-8.483 * * *$ & $-6.985^{* *}$ & $0.074 * * *$ & $0.148 * * *$ & $0.083 * * *$ & 0.088 \\
\hline & $(0.9262)$ & $(2.7975)$ & $(0.0121)$ & $(0.0474)$ & $(0.0136)$ & $(0.0555)$ \\
\hline \multirow[t]{2}{*}{ Stratum 7} & $-6.498 * * *$ & -0.902 & $0.0418^{* * *}$ & $0.063^{*}$ & $0.047 * * *$ & -0.043 \\
\hline & $(0.7701)$ & $(2.3260)$ & $(0.0092)$ & $(0.0354)$ & $(0.0120)$ & $(0.0456)$ \\
\hline \multirow[t]{2}{*}{ Stratum 8} & $-5.375^{* * *}$ & $-4.621 * * *$ & $0.060 * * *$ & $0.078 * * *$ & $0.031 * * *$ & 0.019 \\
\hline & $(0.2888)$ & $(0.8983)$ & $(0.0033)$ & $(0.0143)$ & $(0.0040)$ & $(0.0162)$ \\
\hline \multirow[t]{2}{*}{ Stratum 9} & $-6.015^{* * *}$ & $-2.715^{*}$ & $0 . .050^{* * *}$ & $0.097 * * *$ & $0.029 * * *$ & 0.004 \\
\hline & $(0.4990)$ & (1.4318) & $(0.0054)$ & $(0.0218)$ & $(0.0077)$ & $(0.0280)$ \\
\hline \multirow[t]{2}{*}{ Stratum 10} & $-5.781 * * *$ & $-5.039 * * *$ & $0.048 * * *$ & $0.145^{* * *}$ & $0.040 * * *$ & $0.068 * * *$ \\
\hline & $(0.4331)$ & $(1.2059)$ & $(0.0047)$ & $(0.0181)$ & $(0.0065)$ & $(0.0234)$ \\
\hline \multirow[t]{2}{*}{ Stratum 11} & $-5.596^{* * *}$ & $-4.643 * * *$ & $0.061 * * *$ & $0.115^{* * *}$ & $0.037 * * *$ & $0.031 * *$ \\
\hline & $(0.2503)$ & $(0.7071)$ & $(0.0029)$ & $(0.0111)$ & $(0.0038)$ & $(0.0137)$ \\
\hline \multirow[t]{2}{*}{ Stratum 12} & $-6.369 * * *$ & $-4.426^{* * *}$ & $0.047 * * *$ & $0.097 * * *$ & $0.032 * * *$ & $0.057 * * *$ \\
\hline & $(0.2605)$ & $(0.7247)$ & $(0.0028)$ & $(0.0106)$ & $(0.0054)$ & $(0.0147)$ \\
\hline \multirow[t]{2}{*}{ Stratum 13} & $-6.112 * * *$ & $-4.187 * * *$ & $0.049 * * *$ & $0.060 * * *$ & $0.032 * * *$ & $0.037 * *$ \\
\hline & $(0.3400)$ & $(0.8429)$ & $(0.0036)$ & $(0.0123)$ & $(0.0053)$ & $(0.0167)$ \\
\hline \multirow[t]{2}{*}{ Stratum 14} & $-5.413 * * *$ & $-3.528 * * *$ & $0.060^{* * *}$ & $0.110^{* * *}$ & $0.034 * * *$ & $0.059^{* * *}$ \\
\hline & $(0.3126)$ & $(0.8004)$ & $(0.0034)$ & $(0.0123)$ & $(0.0053)$ & $(0.0168)$ \\
\hline \multirow{2}{*}{ Stratum 15} & $-5.488 * * *$ & $-5.503 * * *$ & $0.047 * * *$ & $0.062 * * *$ & $0.041 * * *$ & $0.030 * *$ \\
\hline & $(0.2502)$ & $(0.6200)$ & $(0.0027)$ & $(0.0088)$ & $(0.0044)$ & $(0.0132)$ \\
\hline \multirow[t]{2}{*}{ Stratum 16} & $-5.163 * * *$ & $-4.873 * * *$ & $0.056 * * *$ & $0.025^{* *}$ & $0.024 * * *$ & 0.014 \\
\hline & $(0.4346)$ & $(0.9086)$ & $(0.0045)$ & $(0.0116)$ & $(0.0074)$ & $(0.0187)$ \\
\hline \multirow[t]{2}{*}{ Stratum 17} & $-5.076 * * *$ & $-4.868 * * *$ & $0.041 * * *$ & $0.068 * * *$ & $0.040 * * *$ & -0.003 \\
\hline & $(0.4473)$ & $(0.9728)$ & $(0.0047)$ & $(0.0129)$ & $(0.0080)$ & $(0.0207)$ \\
\hline \multirow[t]{2}{*}{ Stratum 18} & $-5.093 * * *$ & $-4.512 * * *$ & $0.039 * * *$ & $0.052 * * *$ & $0.041 * * *$ & -0.014 \\
\hline & $(0.3369)$ & $(0.6112)$ & $(0.0035)$ & $(0.0064)$ & $(0.0064)$ & $(0.0132)$ \\
\hline \multirow[t]{2}{*}{ Stratum 19} & $-4.174 * * *$ & $-6.382 * * *$ & $0.032^{* *}$ & 0.008 & $0.071^{* *}$ & $0.117 * * *$ \\
\hline & (1.4076) & (1.6705) & $(0.0136)$ & $(0.0133)$ & $(0.0302)$ & $(0.0346)$ \\
\hline \multirow[t]{2}{*}{ Stratum 20} & $-6.791 * * *$ & $-5.126^{* *}$ & 0.018 & 0.004 & 0.049 & 0.029 \\
\hline & $(2.5747)$ & $(02.0468)$ & $(0.0195)$ & $(0.0145)$ & $(0.0547)$ & $(0.0438)$ \\
\hline \multirow[t]{2}{*}{ Stratum 21} & -4.914 & -1.246 & -0021 & -0.017 & -0.1454 & -0.075 \\
\hline & (10.4899) & $(6.6240)$ & $(0.0589)$ & $(0.0346)$ & $(0.2324)$ & $(0.1495)$ \\
\hline \multirow[t]{2}{*}{ Slope } & $0.085^{* * *}$ & -0.079 & $-0.002 * * *$ & -0.007 & -0.000 & -0.002 \\
\hline & $(0.0302)$ & $(0.0713)$ & $(0.0003)$ & $(0.0009)$ & $(0.000)$ & $(0.0014)$ \\
\hline cons & -6.7419 & $-3.492 * * *$ & $0.072 * * *$ & $0.176^{* * *}$ & $0.036^{* * *}$ & $0.060 * * *$ \\
\hline
\end{tabular}


Note: Standard errors in braket, * $p<0.10, * * p<0.05, * * * p<0.01$; In the regressions, we control the variables of age, age square, gender, married, out year, ttlfam, outfam, job type, firm type and work type of migrant. All specifications have year fixed effects, city fixed effects, and individual's income-level and education-level controls, clustered at the individual level. Rural identification indicates immigrants who accept the health education none urban citizenship acquisition; citizenship identification indicates immigrates who accept health education is urban citizenship acquisition. Propensity scores were generated by a Probit and OLS regression model .Propensity score strata were balanced such that mean values of covariates did not significantly differ between rural citizenship and urban citizenship.

Table 9 Heterogeneous Treatments Effects of Urban Citizenship acquisition on Second Choice Nodes (SM)

\begin{tabular}{|c|c|c|c|c|c|c|}
\hline & $\begin{array}{c}\text { SR } \\
\text { (Rural } \\
\text { Identification) }\end{array}$ & $\begin{array}{c}\text { SR } \\
\text { (Citizenship } \\
\text { Identification) }\end{array}$ & $\begin{array}{c}\text { SMI } \\
\text { (Rural } \\
\text { Identification) }\end{array}$ & $\begin{array}{c}\text { SMI } \\
\text { (Citizenship } \\
\text { Identification) }\end{array}$ & $\begin{array}{c}\text { HP } \\
\text { (Rural } \\
\text { Identification) }\end{array}$ & $\begin{array}{c}\text { HP } \\
\text { (Citizenship } \\
\text { Identification) }\end{array}$ \\
\hline \multirow[t]{2}{*}{ Stratum 2} & 2.069 & -0.113 & $0.0795 * * *$ & 0.05 & $0.0526^{*}$ & 0.0272 \\
\hline & (1.6439) & (3.699) & $(0.0233)$ & $(0.0626)$ & $(0.0233)$ & $(0.0753)$ \\
\hline \multirow[t]{2}{*}{ Stratum 3} & $-0.920 *$ & 0.623 & $0.0531 * * *$ & $0.0907 * * *$ & $0.0474 * * *$ & $0.1399 * * *$ \\
\hline & $(0.5360)$ & (1.6979) & $(0.0063)$ & $(0.0284)$ & $(0.0079)$ & $(0.0356)$ \\
\hline \multirow[t]{2}{*}{ Stratum 4} & -2.845 & -0.007 & $0.0510 * * *$ & $0.1130 * * *$ & $0.0522 * * *$ & $0.1301 * *$ \\
\hline & $(0.5296)$ & (1.5578) & $(0.0069)$ & $(0.0286)$ & $(0.0058)$ & $(0.0321)$ \\
\hline \multirow[t]{2}{*}{ Stratum 5} & 0.313 & $-5.1753 * * *$ & $0.0392 * * *$ & $0.0922 * * *$ & $0.0525 * * *$ & 0.0488 \\
\hline & $(0.1843)$ & (1.0402) & $(0.0046)$ & $(0.0164)$ & $(0.0058)$ & $(0.0191)$ \\
\hline \multirow[t]{2}{*}{ Stratum 6} & $1.103 * * *$ & $1.004 * * *$ & $0.0403 * * *$ & $0.0684 * * *$ & $0.0427 * * *$ & $0.0414 * * *$ \\
\hline & $(0.4451)$ & $(0.5163)$ & $(0.00192)$ & $(0.00742)$ & $(0.00282)$ & $(0.0109)$ \\
\hline \multirow[t]{2}{*}{ Stratum 7} & $-0.882 *$ & 1.218 & $0.0294 * * *$ & $0.0564 * * *$ & $0.0704 * * *$ & $0.0495^{*}$ \\
\hline & $(0.3967)$ & (1.074) & $(0.0042)$ & $(0.0152)$ & $(0.007)$ & $(0.0239)$ \\
\hline \multirow[t]{2}{*}{ Stratum 8} & -0.191 & $-5.221 * * *$ & $0.0290 * * *$ & $0.086^{* * * *}$ & $0.0420^{* *}$ & $0.061 * * *$ \\
\hline & $(0.3172)$ & $(0.554)$ & $(0.0034)$ & $(0.0137)$ & $(0.0057)$ & $(0.0206)$ \\
\hline \multirow[t]{2}{*}{ Stratum 9} & 0.299 & 0.571 & $0.0419 * * *$ & $0.0988^{* * *}$ & $0.0469 * * *$ & 0.024 \\
\hline & $(0.3559)$ & $(0.8102)$ & $(0.004)$ & $(0.0136)$ & $(0.0061)$ & $(0.0176)$ \\
\hline Stratum & -0.0462 & 0.3221 & $0.0281 * * *$ & $0.0789 * * *$ & $0.0585 * * *$ & 0.0065 \\
\hline 10 & $(0.3071)$ & $(0.8273)$ & $(0.0033)$ & $(0.0135)$ & $(0.0060)$ & $(0.0194)$ \\
\hline Stratum & $0.5329 * *$ & $1.098 * * *$ & $0.0321 * * *$ & $0.0672 * * *$ & $0.0301 * * *$ & $0.0342 * * *$ \\
\hline 11 & $(0.2020)$ & $(0.4727)$ & $(0.0022)$ & $(0.00732)$ & $(0.0037)$ & $(0.011)$ \\
\hline Stratum & $0.863 * * *$ & 0.5728 & $0.0264 * * *$ & $0.0413 * * *$ & $0.0275^{* * *}$ & $0.0472 * * *$ \\
\hline 12 & $(0.2571)$ & $(0.6731)$ & $(0.0027)$ & $(0.0109)$ & $(0.0049)$ & $(0.0162)$ \\
\hline Stratum & 0.695 & $-0.0193 * * *$ & $0.0310 * * *$ & $0.0474 * * *$ & $0.0223 * * *$ & $0.0417 * * *$ \\
\hline 13 & $(0.2752)$ & $(0.7172)$ & $(0.0029)$ & $(0.00375)$ & $(0.0057)$ & $(0.0183)$ \\
\hline Stratum & $-5.538 * * *$ & $1.891 * * *$ & $0.0298 * * *$ & $0.041 * * *$ & $0.0427 * * *$ & 0.011 \\
\hline 14 & $(0.575)$ & $(0.676)$ & $(0.0029)$ & (0.0109) & $(0.0056)$ & $(0.0149)$ \\
\hline Stratum & $1.586 * * *$ & $2.575^{* * *}$ & $0.0148 * * *$ & $0.0426 * * *$ & $0.0491 * * *$ & 0.011 \\
\hline 15 & $(0.4014)$ & $(0.6731)$ & $(0.0042)$ & $(0.0106)$ & $(0.0080)$ & $(0.0153)$ \\
\hline Stratum & 0.3423 & $2.977 * * *$ & $0.0148 * * *$ & $0.0450 * * *$ & $0.0498 * * *$ & $-0.0213 * * *$ \\
\hline 16 & $(0.4070)$ & $(0.6229)$ & $(0.0042)$ & $(0.0085)$ & $(0.0090)$ & $(0.0146)$ \\
\hline Stratum & 0.444 & 1.936 & 0.0200 & $0.0395^{* * *}$ & $0.0777 * * *$ & $-0.0415 * * *$ \\
\hline 17 & $(0.8399)$ & (1.379) & $(0.0094)$ & $(0.0129)$ & $(0.0186)$ & $(0.032)$ \\
\hline Stratum & $2.702 *$ & $5.450 * * *$ & 0.0190 & 0.0141 & 0.0234 & 0.0338 \\
\hline
\end{tabular}




\begin{tabular}{ccccccc}
18 & $(1.303)$ & $(1.5515)$ & $(0.0134)$ & $(0.0966)$ & $(0.0272)$ & $(0.0301)$ \\
Stratum & $3.354^{* * *}$ & $3.3759^{* *}$ & $0.0292^{* * *}$ & -0.00148 & -0.0348 & $-0.006 * * *$ \\
19 & $(1.1427)$ & $(1.302)$ & $(0.0112)$ & $(0.0105)$ & $(0.023)$ & $(0.027)$ \\
Stratum & 0.784 & $3.589^{* *}$ & $0.0234^{* * *}$ & $0.0203^{* * *}$ & $0.0395^{* * *}$ & 0.0141 \\
20 & $(0.741)$ & $(0.7327)$ & $(0.0068)$ & $(0.0538)$ & $(0.0167)$ & $(0.0162)$ \\
Stratum & 2.500 & 2.7651 & 0.0318 & 0.01591 & 0.0076 & -0.0530 \\
21 & $(1.987)$ & $(2.1179)$ & $(0.0210)$ & $(0.0138)$ & $(0.0450)$ & $(0.0479)$ \\
Stratum & -3.05 & 0.196 & 0.0183 & 0.0100 & 0.0198 & $0.1678^{* * *}$ \\
22 & $(2.487)$ & $(2.1577)$ & $(0.0244)$ & $(0.0167)$ & $(0.0566)$ & $(0.0488)$ \\
Stratum & 1.061 & 2.1057 & 0.0176 & 0.00137 & 0.0654 & 0.0498 \\
23 & $(2.437)$ & $(1.8189)$ & $(0.0213)$ & $(0.0166)$ & $(0.0561)$ & $(0.0402)$ \\
Slope & $0.059^{* *}$ & $0.1747^{* * *}$ & $-0.00161^{* * *}$ & -0.00469 & $-0.00131^{* * *}$ & $-0.0036^{* * *}$ \\
& $(0.0208)$ & $(0.0393)$ & $(0.0002)$ & $(.00042)$ & $(0.00038)$ & $(0.00082)$ \\
cons & 0.1425 & -0.590 & $0.049^{* * *}$ & $0.1088^{* * *}$ & $0.054^{* * *}$ & $0.071^{* * *}$ \\
\hline
\end{tabular}

Note: Standard errors in bracket, $* p<0.10,{ }^{* *} p<0.05, * * * p<0.01$; In the regressions, we control the variables of age, agesquare,gender, married, out year, ttlfam, outfam, job type, firm type and work type of migrant. All specifications have year fixed effects, city fixed effects, and individual's income-level and education-level controls, clustered at the individual level. Rural identification indicates immigrants who accept the health education none urban citizenship acquisition; citizenship identification indicates immigrates who accept health education is urban citizenship acquisition. Propensity scores were generated by a Probit and OLS regression model .Propensity score strata were balanced such that mean values of covariates did not significantly differ between rural citizenship and urban citizenship.

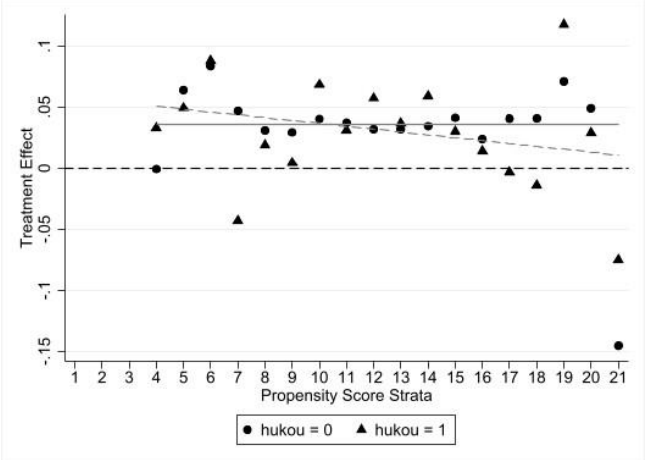

a) Accept Health education and None-acception

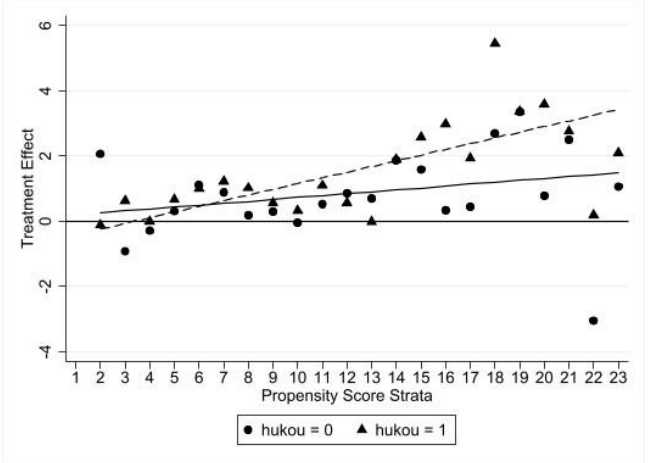

b) Lower health education and higher health education

FIGURE 11 Health education heterogeneous effects on urban residents (Saving Rates)

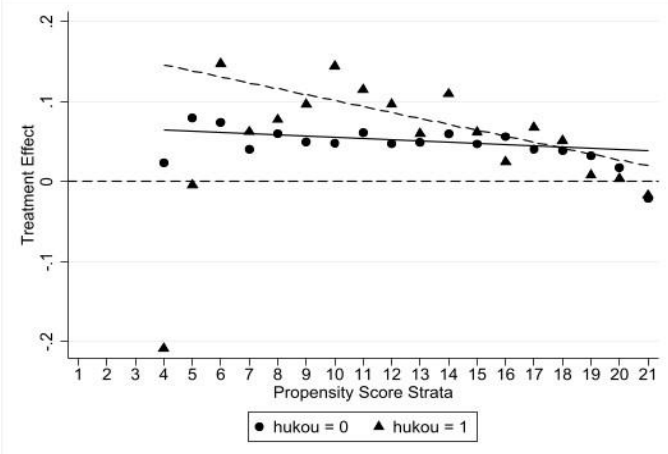

a) Accept Health education and None-acception

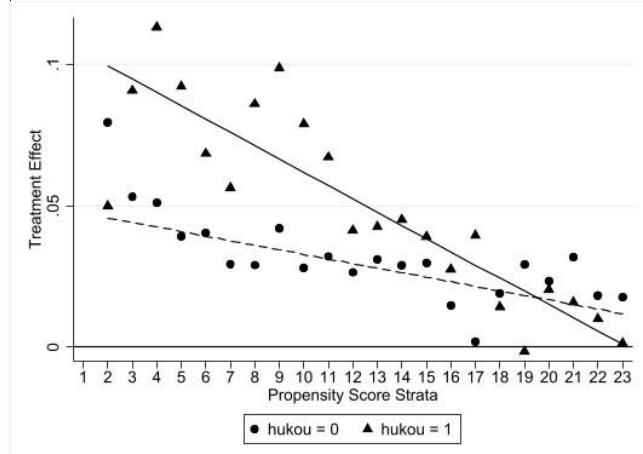

b) Lower health education and higher health education

FIGURE 12 Health education heterogeneous effects on urban residents (Social Medical Insurance) ${ }^{11}$

11 Hukou=1 indicates migrants who are urban citizenship acquisition. Hukou=0 means migrants who are rural citizenship acquisition. 


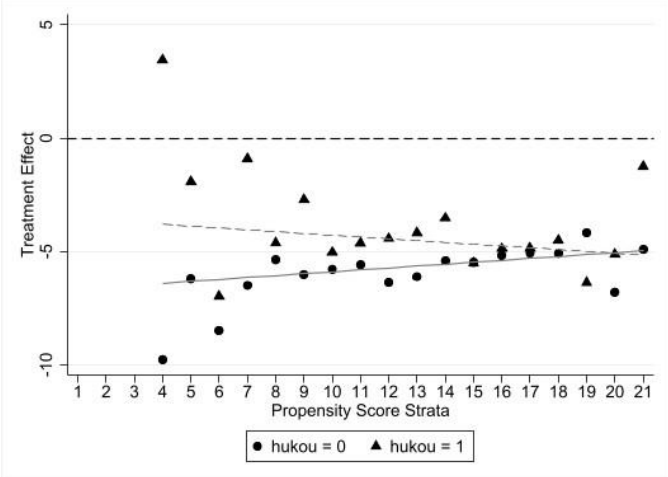

a) Accept Health education and None-accepting

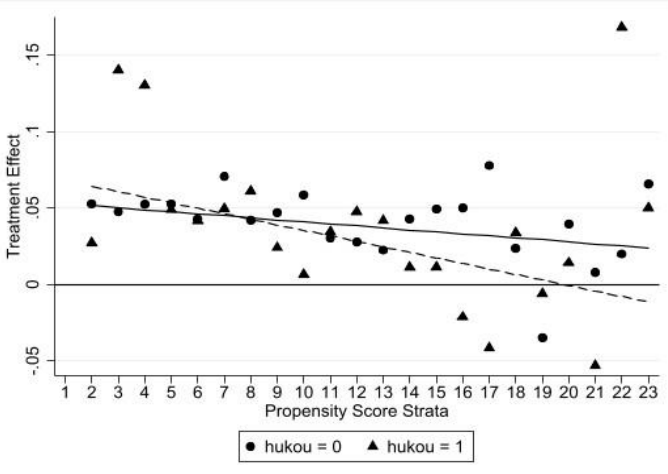

b) Lower health education and higher health education

FIGURE 13 Health education heterogeneous effects on urban residents (House Purchasing)

\section{Discussion}

Under the policy of "Health China," This paper analyzes the relation between health education and 720,900 migrants' economic behaviors from a causals effects perspective. The significant studies reported on how economic reputation leads to healthy, few kinds of literature exploring the influence of continuous health education on economic behavior, especially from immigrants. The guide that our discussions related to whether or not the generation causes heterogeneous effects of health education, and whether health education is equality among rural and urban.

There are three essential discussions from our analysis - the first discussion links to continuous health educations. We divide health education into two nodes through health educations selfness investment from immigrants. The first node defines whether to accept health education, and the seconds' node represents whether accept higher health educations. Based on the theory of sequential decisions, these nodes identify the effects of health education on immigrant's perspectives. It is necessary to discuss the differential of health education choice from immigrants, which indicates that increasing accept health education rates among immigrants is more efficient for stimulating domestic economics than continuous health educations investment.

The link to the second discussion is the causal effects of health education. We adopt variables of health documents in villages as instruments variable through Extend Regression Model (ERM) to eliminate potential endogenous in the surveys. We also analyze the average treatment effects in a sequential decision model. While it is impossible to remove endogenous issues entirely, it could supply a new perspective of research health education effects on the effects of the casual in the future. As a result, health education on saving rates shape invert $U$. The effects were more significant adverse effects for those who acquired health education in the first choice. Higher health education and lower health education have no difference on participating social medical insurance and purchasing house.

The third essentials discussion is heterogeneity treatment effects. The current challenge of global health is health education inequality in developing countries. We concern about the differential effects of health educations on intergeneration and citizenship through heterogeneous treatments effects. Which not only solves the endogenous issues but also precisely identifies whether survival gap between different groups. As a result, it is not wise for young immigrants to stimulate their consumption through continuous health education.

The critical factors of recovering economics through health education are rural-urban equality on health infrastructure. In addition, our studies fill up the gap about health education and 
immigrants' economic behaviors, and we highlight the challenge of global health is health education equality in developing countries. We believe improving rates of accepting health education cover among immigrants more efficient than increasing the rates of accepting higher health education.

\section{Limitations}

While we believe our study to have been sufficiently successful, several limitations with data still survive. A critical issue in interpreting these results is that the data available in this paper provide several bare assertions. Although we have discussed the influence of health education of migrants on their economic behavior, while survived some limitations on the improvement of health education drive the consumption tendency of migrants. Due to CMDS consumption data's limitations, we cannot provide more evidence of migrant consumption in various aspects. However, at least we can confirm the decrease in their savings rate and the increase in their participation in social health security, and the probability of purchasing houses.

\section{Conclusion}

This paper adopts the 720,900-immigration sample to evaluate health education continuous values for immigrants 'economic behaviors under the sequential choice model. We also analyze the heterogeneity treatment effects in intergeneration, and urban citizenship aspects through decompose health education values. We find very confident evidence for health education's influence on economic behaviors. Firstly, aggregate $1 \%$ health education would decrease $13.4 \%$ saving rates; improve $22.1 \%$ probability of participating social, medical insurance and $3.61 \%$ purchasing house in first health educational nodes. Importantly, all results supported our three hypotheses. However, Aggregate 1\% health education would be increasing 3.07\% saving rate, improve $9.522 \%$ probability of participating social medical insurance and $1.06 \%$ purchasing house in higher health education sample.

In terms of heterogeneity effects on intergeneration. We find health education has positive effects on consumption, participating social health medical and purchasing house, especially for the previous generation, however higher health education is not wise to stimulating young generation consumption. Combined urban citizenship acquisition, we find that health education induces significant purchasing houses among rural citizens in all health educational choice nodes, especially in higher education nodes. Those results provide evidence that health education improves consumption economic behavior. However, higher health education is not wise to stimulate urban citizenship and the young generation's consumption.

Overall, our study is the most comprehensive analysis literature of health education and economic behaviors. Our results show that the importance of creating growing-friendly good health education services. The effects of health education services ought to allow individuals to make choices that allow them to enjoy as equally as possible public services' externalities.

\section{Declarations section}

\section{Competing Interests}

We declare that the research was conducted in the absence of any commercial or financial relationships that could be construed as a potential conflict of interest.

\section{Author Contributions}

Chunfeng Dong: Data Collections.

jialu You: Writing- Original draft; Visualization; Writing- Reviewing and Editing; Methodology; Empirically Analyze. 


\section{Acknowledgements}

We acknowledges the research support of central research funds of university $(\mathrm{CN})$ of shanghai university of finance and economics(No.20200521), and studies suggestions from 2021CES annuls.

\section{Availability of Data and Materials}

http://www.geodata.cn/wjw/\#/data/classify/population/yearList. Public data from China Migrants Surveys.

\section{Author Information}

Jinhua Z: Professor of Shanghai University of Finance and Economics. The prominent author fields of Labor Economics, Education Economics, and Agriculture Economics. Already published numerous articles and books in top Journals.

Jialu.Y: Ph.D. student of Shanghai University of Finance and Economics. The primary author fields of Labor Economics; Finance Economics. Already published numerous articles on CAER, JIAE, and IEEE.

Chunfeng.D: Ph.D. student of Shanghai University of Finance and Economics. The primary author fields of urban economics. Already published numerous articles.

\section{Funds}

The research support of central research funds of university $(\mathrm{CN})$ of shanghai university of finance and economics(No.20200521)

\section{Ethical Approval and Consent to participate}

Ethics approval and consent to participate Not applicable

\section{Consent for publication}

Not applicable

\section{Reference}

Bahadir Dursun, Resul Cesur, Naci Mocan,2018. The Impact of Education on Health Outcomes and Behaviors in a Middle-Income, Low-Education Country,Economics \& Human Biology, 31:94-114.

Beck, T., Levine, R., Levkov, A., 2010. Big bad banks? The winners and losers from bank deregulation in the United States. Journal of Finance 65(5), 1637-1667.

Berens EM., Vogt D., Messer M., Hurrelmann K., Schaeffer D., 2016. Health literacy among different age groups in Germany: results of a cross-sectional survey. BMC Public Health 16 (1):115-151.

Boone J., 2019. Health provider networks with private contracts: is there under-treatment in narrow networks. Journal of Health Economics 67(12).

Brigitte, 2014. Employment-based health insurance and job mobility: is there evidence of job-lock. The Quarterly Journal of Economics 109 (1):27-54.

Callaway, Brantly and Sant'Anna, Pedro H. C.2019, Difference-in-Differences with Multiple Time Periods.SSRN: https://ssrn.com/abstract=3148250 or http://dx.doi.org/10.2139/ssrn.3148250

Chamon, M. D., Prasad, E. S., 2010. Why are saving rates of urban households in China rising. American Economic Journal: Macroeconomics, American Economic Association 2(1), 93-130.

Civitelli, G., Tarsitani, G., Rinaldi, A. et al.2020. Medical education: an Italian contribution to the discussion on global health education. Global Health. 16(30).

Deaton, A., 2013. The great escape: health, wealth, and the origins of inequality. Princeton: Princeton University Press.

Dupas P., Miguel E., 2017.Impacts and determinants of health levels in low-income countries .Handbook of Economic Field Experiments 3-93, North-Holland Press. 
Duflo, Esther, Pascaline Dupas, and Michael Kremer. 2015. "Education, HIV, and Early Fertility: Experimental Evidence from Kenya." American Economic Review, 105 (9): 2757-97.

Field and Gold, 1998. Summarizing population health: directions for the development and application of population metrics. Washington (DC): National Academies Press (US).

Font and Cowell, 2019. Incorporating inequality aversion in health-care priority setting. Social Justice Research 32(2): 172-185.

Heckman, John Eric Humphries, and Gregory Veramendi 2018.Returns to Education: The Causal Effects of Education on Earnings, Health, and Smoking.Journal of Political Economy126(s1):197-246.

Hee Yun Lee, 2020. Parents' functional health literacy is associated with children's health outcomes: implications for health practice, policy, and research. Children and Youth Services Review 110(1):81-87.

Hilary W., Hoynes, 2006 .What mean impacts miss: distributional effects of welfare reform experiments. American Economic Review 96(4):988-1102.

Jacob Goldin, 2020. Health insurance and mortality: experimental evidence from taxpayer outreach. The Quarterly Journal of Economics 24 (9):1-49.

Jie C., Xi Y., 2020. How is the potential consumption of citizenization of migrant population? Based on estimation on income elasticity of consumption of China's migrant population in the new era. Urban and Environmental Studies 1, 34-54.

Jorge Rodrguez., Dynamic Treatment Effects of Job Training.NBER.DOI:10.3386/w25408.

Katharina Janke, David W. Johnston, Carol Propper, Michael A. 2020.Shields, The causal effect of education on chronic health conditions in the UK,Journal of Health Economics, 70:167-296.

Muller, A., 2017. Functional integration of China's social protection: recent and long-term trends of institutional change in health and pension insurance. Asian Survey 57(6), 1110-1134.

Neuman, 2008. Quit your job and get healthier? The effect of retirement on health. Journal of Labor Research 29:117201.

Pascaline Dupas, Edward Miguel, 2016.Impacts and determinants of health levels in low-income countries. NBER Working Papers 22235, National Bureau of Economic Research. Inc.

Pentek M., 2014. Subjective expectations at biological therapy initiation: a survey of rheumatoid arthritis patients and rheumatologists. Eur. J. Health Econ. 15, 83-92

Rappange, 2016. Rational expectations? An explorative study of subjective survival probabilities and lifestyle across Europe. Health Expectations 19 (1):121-137.

Robert R., Weathers ,2012 .The effect of expanding access to health insurance on the health and mortality of Social Security Disability Insurance beneficiaries. J. Health Econ . 31 (6):863-875.

Shuang, M. A., Gan, L. I., 2011. The effect of the new rural cooperative medical system on rural household food consumption. China Economic Quarterly 10(1), 249-270.

Simonds ,1978. Health education as social policy. Health Education \& Behavior 1(3):177-191.

Toçi E., Burazeri G., Kamberi H., Jerliu N., Sørensen K., Brand H.,2014. Socio-economic correlates of functional health literacy among patients of primary health care in Kosovo. Public Health 128(9):842-850.

Wagstaff, A., Lindelow, M., Jun, G., et al., 2009. Extending health insurance to the rural population: An impact evaluation of China's new cooperative medical scheme. Journal of Health Economics 28(1), 1-19.

Weiss, B. D., 2015. Association of health literacy with adherence to screening mammography guidelines. Obstetrics \& Gynecology 125(4), 852-859.

Xian Huang, 2020. Impact of urban-rural health insurance integration on health care: evidence from rural China. China Economic Review 64 (12):101543.

Xu, X., Reed, W. R., Menclova, A., 2020. Social capital and health: a meta-analysis. Journal of Health Economics, 
$72,102317$.

Yu Xie, Jennie E. Brand, and Ben Jann, 2012 .Estimating Heterogeneous Treatment Effects with Observational Data. Sociol Methodol. 42(1):314-347.

Zajacova. 2018.The relationship between education and health: reducing disparities through a contextual approach Annu Rev Public Health. 39(1): 273-289. 